Vet. Res. (2009) 40:13

Www.vetres.org

DOI: $10.1051 /$ vetres:2008051

C INRA, EDP Sciences, 2009

Review article

\title{
Experimental evaluation of foot-and-mouth disease vaccines for emergency use in ruminants and pigs: a review
}

\author{
Sarah J. CoX*, Paul V. BARnETT \\ Institute for Animal Health, Pirbright Laboratory, Ash Road, Pirbright, Woking, \\ Surrey, GU24 0NF, United Kingdom
}

(Received 2 June 2008; accepted 27 November 2008)

\begin{abstract}
Changes to foot-and-mouth disease (FMD) control policies since 2001 mean that emergency vaccination must be considered more readily as a control measure in the future. Since field application of vaccine for emergency use has only rarely been applied, the effectiveness of single dose administration, as a control measure in an outbreak situation, is poorly understood. In this review we consider all the available experimental data from studies utilizing either experimental or readily available, commercially produced vaccines, in order to assess their likely effectiveness as an additional means of controlling FMD transmission and spread in an emergency. Overall it is concluded that such vaccines offer an additional and valuable means of FMD control for both ruminants and pigs. They are able to reduce clinical disease, sub-clinical infection and excretion and onward transmission of virus. However, to be most effective, vaccination should be rapidly applied to give maximum opportunity for immunity to develop. We also identify areas for future research and emphasize the importance of vaccine efficacy studies in providing data for models that can help to predict the efficacy of differing FMD control strategies.
\end{abstract}

review / foot-and-mouth disease / emergency vaccine / experimental studies

\section{Table of contents}

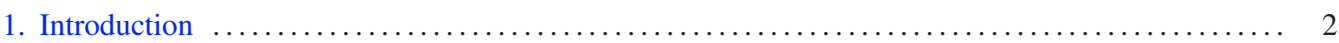

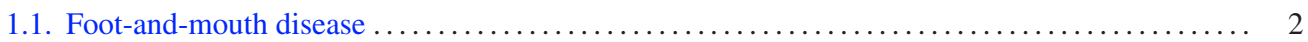

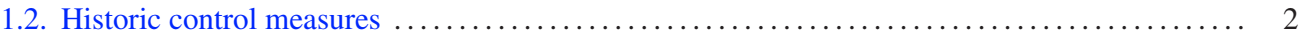

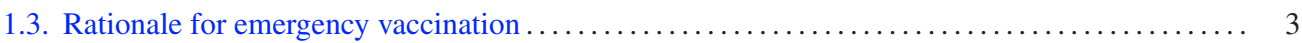

2. Efficacy of FMD vaccines to protect against clinical disease in animals experimentally challenged with unvaccinated FMDV infected donor animals $\ldots \ldots \ldots \ldots \ldots \ldots \ldots \ldots \ldots \ldots \ldots \ldots \ldots \ldots, 4$

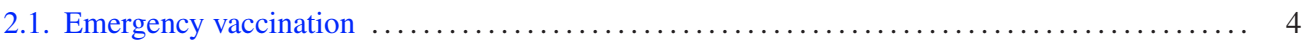

2.2. Vaccine studies demonstrating protection against clinical disease using indirect contact

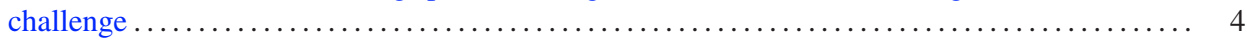

2.3. Vaccine studies demonstrating protection against clinical disease using direct contact challenge 8

3. Efficacy of FMD vaccines to protect against sub-clinical infection, reduce virus excretion and persistence in animals experimentally challenged with unvaccinated FMDV infected donor animals 8

3.1. Prevention of sub-clinical infection, virus excretion and persistence in cattle $\ldots \ldots \ldots \ldots \ldots . \quad 8$

3.2. Prevention of sub-clinical infection, virus replication and persistence in sheep . . . . . . . . . 13

3.3. Influence of antigen payload on sub-clinical infection, virus replication and persistence in sheep 13

3.4. Prevention of sub-clinical infection and virus excretion in pigs $\ldots \ldots \ldots \ldots \ldots \ldots \ldots \ldots \ldots$

* Corresponding author: Sarah.cox@bbsrc.ac.uk 
4. Effect of FMD vaccines on preventing FMDV transmission to naïve and vaccinated animals from

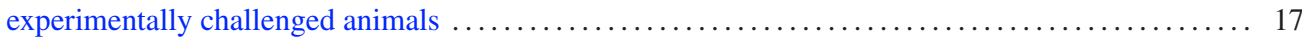

4.1. Transmission from vaccinated to naïve, in-contact animals $\ldots \ldots \ldots \ldots \ldots \ldots \ldots \ldots \ldots \ldots \ldots \ldots$

4.2. Transmission between homogeneously treated groups of animals $\ldots \ldots \ldots \ldots \ldots \ldots \ldots \ldots \ldots$

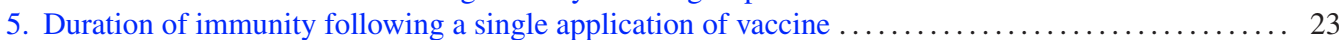

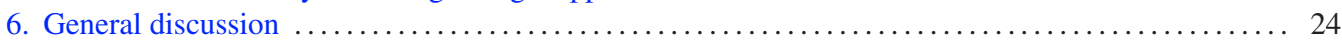

\section{INTRODUCTION}

\subsection{Foot-and-mouth disease}

Foot-and-mouth disease (FMD) is a highly contagious disease of domesticated ruminants and pigs which can also affect a large number of wildlife species [18]. FMD was the first animal disease attributed to infection by a virus [41], although the disease itself had been described as early as the sixteenth century in Italy [35]. The causal agent of the disease is a small (25-30 nm), icosahedral non-enveloped RNA virus classified within the Aphthovirus genus, as a member of the Picornaviridae $[12,61]$. FMD is a vesicular disease, the clinical severity of which varies with the strain of foot-and-mouth disease virus (FMDV), as well as the infecting dose, the species and individual susceptibility of the host. Direct or indirect contact with FMDV infected animals can result in susceptible animals becoming diseased or sub-clinically infected. In ruminants, but not pigs, complete clearance of virus from the pharynx may be delayed giving rise to persistently infected carriers. The main route of virus entry, in natural infections, is the respiratory tract through inhalation of airborne virus, although virus may also gain entry through oral ingestion, or damaged epithelium [2]. There are seven immunologically distinct serotypes of FMDV: O, A, C, SAT (South African Territories) 1, SAT 2, SAT 3 and Asia 1, and infection (or vaccination) with one serotype does not confer immunity to another [16]. Additionally, within serotype there are subtypes against which vaccines of the same serotype will fail to fully protect [53].

Various studies have demonstrated that infected animals can excrete FMDV shortly before the development of clinical signs and that peak excretion occurs around the time of onset of clinical disease [2]. During the course of the disease an animal produces virus in excretions and secretions such as saliva, nasal and lachrymal fluid, milk, expired breath, urine and faeces, which results in massive environmental contamination [2]. FMD can rapidly spread in susceptible populations causing severe economic losses to both dairy and meat producing businesses as a result of lost fertility, productivity and mortality of young livestock. However, wider effects on a country's ability to trade and export animals and animal products, and the cost of control measures to prevent entry or eliminate FMDV accounts for its main economic impact. It is the disease most feared by livestock holders and veterinarians and is an Office International des Epizooties (OIE) listed disease [44]. Not surprisingly, the issue of control is regarded as a high priority.

\subsection{Historic control measures}

Although FMD remains widely distributed throughout the world and is endemic in many regions, including parts of Africa, the Middle East, Asia and South America (sporadic outbreaks), it has been successfully eradicated, or prevented from gaining a foothold, in other areas by a variety of control strategies $[17,37,40,43,64,65]$. Countries which have traditionally remained free of the disease, such as Australia, New Zealand, and Japan, primarily due to their geographical location, and also North America, have maintained their freedom by imposing strict import/quarantine legislation. Incursion of disease, which has only occurred very occasionally in some of these countries, has been dealt with by slaughter of infected animals and their contacts. The United Kingdom, Ireland, and Scandinavian countries in which incursions occurred more regularly, often on an annual basis, developed a more 
organized control program, and as early as 1892 the UK applied a 'stamping-out' policy, which included not only the slaughter and destruction of infected animals and their immediate contacts, but thorough cleaning and disinfection. Subsequently, restrictions on movement of susceptible livestock were also introduced, once an outbreak of FMD was confirmed, in order to reduce spread of disease.

Europe and South America, however, were unable to eradicate FMD without the aid of vaccination. Up until the 1950's insufficient vaccine meant that Europe suffered extensive epidemics, but as vaccine production was improved and vaccines became more readily available, annual programs of vaccination were implemented, and the disease was brought under control. In 1985 the European Union (EU) decided to implement a non-prophylactic vaccination policy, which was finally introduced in 1991-1992 and EU member countries became an FMD free zone. South America, where vaccination was also practiced, became disadvantaged as their status as only 'FMD free with vaccination' reduced their export markets in Europe. Therefore they too imposed programs of control during the 1990's which meant that many southern regions of the continent were able to eradicate the disease to become FMD free without the continued use of vaccination. Today vaccines are widely used to control FMD in endemic areas, but frequently socio-economic constraints result in inadequate vaccination programs which provide incomplete protection and, along with lack of border and movement controls, allow the cycle of disease to continue. The limitations to international policies and the inadequacy of funds to co-ordinate worldwide control remain major hurdles which hamper progress towards global eradication of the disease, but planning continues toward progressive control of FMD worldwide [56].

\subsection{Rationale for emergency vaccination}

All FMD free countries need to be continually on their guard against re-introduction of
FMDV and have control measures ready that will reduce transmission and aid rapid elimination of the virus from an area where an outbreak occurs. The implementation of nonvaccination policies for the control of FMD has resulted in domestic livestock populations which are highly susceptible to the disease (as evidenced by the 2001 epidemic in the UK, which spread to Northern Ireland, France and the Netherlands; the 2000-2001 South American outbreaks and the 2007 UK outbreak). Current policy for outbreaks of FMD in many disease-free countries is based upon total slaughter, disposal, movement restrictions and disinfection ('stamping out'). However, within the EU, there is provision to resort to emergency vaccination, particularly should it be considered likely that the outbreak would become extensive, or the logistics of slaughtering a large number of animals are unattainable. However, some concerns remain over the effectiveness of emergency vaccination to control FMD, as questions such as: How fast will protection be achieved? How long will immunity last? Will transmission be reduced? Will persistence go undetected? remain to be fully answered. Additionally, there is often debate over whether the use of emergency vaccination would complicate and delay the regaining of FMD free status which is of great economic importance.

The primary objectives of this review are to draw together available experimental data relating to efficacy of vaccines for emergency use, particularly with regard to providing early protection from disease, subclinical infection and onward transmission of virus. Studies using cattle, sheep and pigs are considered. We also identify areas for future research and emphasize the importance of vaccine efficacy studies in providing data which inform models that help to predict the efficacy of differing FMD control strategies. Specifically, the review will focus on readily available commercially produced FMD vaccines prepared for emergency use from highly concentrated antigen stored over liquid nitrogen. However, reference will be made on occasion to studies which have used experimental vaccines, including the use of 
novel oil adjuvants or where antigen payload was increased as a means of improving vaccine performance.

\section{EFFICACY OF FMD VACCINES TO PROTECT AGAINST CLINICAL DISEASE IN ANIMALS EXPERIMENTALLY CHALLENGED WITH UNVACCINATED FMDV INFECTED DONOR ANIMALS}

\subsection{Emergency vaccination}

The definition of emergency vaccination, in its broadest sense, is the use of vaccines to control an outbreak of FMD in a country, or area, normally free from the disease, in which routine prophylactic vaccination is not practiced. However, occasionally emergency vaccination may also be applied to outbreaks in countries in which vaccine is routinely used, to either boost existing immunity or provide protection against a different serotype, or strain. In the opinion of the authors, an ideal emergency vaccine should have the following characteristics: contain no residual live FMDV and have minimal side effects in adult and newborn animals; rapidly prevent the spread of infection after a single application with minimal dosage; be compatible with serological tests that identify infection in vaccinated animals; be stable under storage once formulated; provide a broad spectrum of antigenic protection; and induce a reasonably long lasting immunity.

Although initially vaccines for emergency use were bulk reserves of formulated vaccine, the development of ultra cold storage of concentrated antigens, which can be specifically formulated into vaccine, as and when required, has become the more accepted strategy, and has lead to the establishment of national or shared antigen banks [6]. Vaccines prepared from such stores are usually formulated to contain higher levels of antigen than conventional prophylactic vaccines, and as a consequence are expected, or shown, to be more potent, providing more rapid immunity and better cross protection within serotype. Emergency vaccines are generally required to achieve a minimum potency, $\mathrm{PD}_{50}(50 \%$ protective dose) of 6, whereas vaccines for prophylactic use are often formulated to at least a potency of $3 \mathrm{PD}_{50}$ [34]. In reality, both types of vaccine, when produced from reputable manufacturers and banks, are usually formulated to provide $\mathrm{PD}_{50}$ values greatly above the minimum stipulated value, (where $\mathrm{PD}_{50}$ is defined as the factor by which the antigen dose may be reduced such that $50 \%$ of the vaccinated animals would be protected). The lack of precision and inherent variability associated with biological potency assay procedures, however, should always be borne in mind $[24,55]$.

When the concept of emergency vaccination was originally considered for contingency use, as a control measure for FMD, very little was known about how well, or rapidly, FMD vaccines would protect cattle, pigs and sheep from disease following a single administration. For prophylactic use the usual regime is an initial shot followed by a booster around 4 to 6 weeks later, which is subsequently followed by further boosts every 4-6 months or annually depending upon the species, life expectancy, worth of the animal and prevailing epidemiological conditions [28]. Clearly, such a regime, developed as a consequence of years of field use, allows sufficient time for the immune response to develop and be maintained before encounter with virus [26]. However, experience of using emergency vaccination is much less than for prophylactic vaccination, and emergency vaccinated animals may be challenged soon after a single immunization; hence experimental work was necessary to investigate the rapidity of protection conferred by vaccines used in this way.

\subsection{Vaccine studies demonstrating protection against clinical disease using indirect contact challenge}

Early work from the late 1960's to 1980's in cattle, pigs and occasionally sheep, that contained high concentrations of FMDV antigen, showed that it was possible to protect all three species from typical FMD lesions on mouth and feet early after a single immunisation (Tabs. I to III) $[29,36$, 38, 59]. Several more studies, carried out 
Table I. Summary table to show experimental design variation and protection from clinical disease in cattle following vaccination with FMD vaccines formulated for emergency use.

\begin{tabular}{|c|c|c|c|c|c|c|c|c|c|c|c|c|c|c|c|}
\hline \multirow{2}{*}{ Breed } & \multirow{2}{*}{ Vaccine } & \multirow{2}{*}{ Challenge } & \multicolumn{12}{|c|}{ Days vaccinated before exposure } & \multirow{2}{*}{ Ref. } \\
\hline & & & 0 & 2 & 3 & 4 & 5 & 7 & 8 & 10 & 12 & 14 & 16 & 21 & \\
\hline Hereford & $\begin{array}{c}\mathrm{A} 119^{\mathrm{a}} \\
10 \mu \mathrm{g} / \mathrm{dose}^{\mathrm{c}} \\
\text { Oil }^{\mathrm{d}}\end{array}$ & $\begin{array}{l}\text { Homologous direct } \\
\text { contact with } 2 \\
\text { infectious cattle (for } \\
10 \text { days?) }\end{array}$ & $0 / 5$ & & & $4 / 4^{b}$ & $3 / 4$ & $4 / 4$ & & $4 / 4$ & & $4 / 4$ & & & [38] \\
\hline $\begin{array}{l}\text { Aberdeen Angus } \\
\text { Friesian cross }\end{array}$ & $\begin{array}{c}\mathrm{O}_{1} \text { BFS } 1860 \\
10 \mu \mathrm{g} / \text { dose } \\
\text { Aqueous }\end{array}$ & $\begin{array}{l}\text { Homologous indirect } \\
\text { aerosol from } 2 \\
\text { infectious pigs for } 1 \mathrm{~h}\end{array}$ & $0 / 12$ & & & $3 / 6$ & & $3 / 6$ & & & & $6 / 6$ & & $18 / 18$ & [29] \\
\hline $\begin{array}{l}\text { Friesian and Friesian } \\
\text { Hereford cross }\end{array}$ & $\begin{array}{c}\mathrm{O}_{1} \text { Lausanne } \\
4.1 \mu \mathrm{g} / \mathrm{dose} \\
\text { Aqueous } \\
\mathrm{O}_{1} \text { Lausanne } \\
4.1 \mu \mathrm{g} / \mathrm{dose} \\
\text { Oil } \\
\end{array}$ & $\begin{array}{l}\text { Homologous indirect } \\
\text { aerosol from } 3 \\
\text { infectious pigs for } 1 \mathrm{~h}\end{array}$ & $0 / 2$ & & & $\begin{array}{l}2 / 2 \\
2 / 2\end{array}$ & & & $3 / 3$ & & $3 / 3$ & & $3 / 3$ & $\begin{array}{l}3 / 3 \\
3 / 3\end{array}$ & [25] \\
\hline $\begin{array}{l}\text { Friesian and Friesian } \\
\text { Hereford cross }\end{array}$ & $\begin{array}{c}\mathrm{C}_{1} \text { Oberbayern } \\
1.9 \mu \mathrm{g} / \text { dose } \\
\text { Aqueous } \\
\mathrm{C}_{1} \text { Oberbayern } \\
1.9 \mu \mathrm{g} / \text { dose } \\
\text { oil } \\
\end{array}$ & $\begin{array}{l}\text { Homologous indirect } \\
\text { aerosol from } 3 \\
\text { infectious pigs for } 1 \mathrm{~h}\end{array}$ & $0 / 2$ & & & $\begin{array}{l}2 / 2 \\
2 / 2\end{array}$ & & & $3 / 3$ & & $3 / 3$ & & $3 / 3$ & $3 / 3$ & [25] \\
\hline $\begin{array}{l}\text { Friesian Hereford } \\
\text { cross? }\end{array}$ & $\begin{array}{c}\text { Asia } 1 \text { India } 8 / 79 \\
4.8 \mu \mathrm{g} / \mathrm{dose} \\
\text { Aqueous } \\
\text { Asia } 1 \text { India } 8 / 79 \\
4.8 \mu \mathrm{g} / \mathrm{dose} \\
\text { Oil } \\
\end{array}$ & $\begin{array}{l}\text { Homologous indirect } \\
\text { aerosol from } 3 \\
\text { infectious pigs for } 1 \mathrm{~h}\end{array}$ & $0 / 2$ & $\begin{array}{l}0 / 3 \\
3 / 3\end{array}$ & $3 / 3$ & $2 / 3$ & & & $6 / 6$ & & $4 / 4$ & & & & $\begin{array}{c}\text { See } \\
\text { footnote } 1\end{array}$ \\
\hline $\begin{array}{l}\text { Holstein Friesian } \\
\text { cross }\end{array}$ & $\begin{array}{c}\mathrm{O}_{1} \text { Manisa } \\
?(18 \text { PD } 50) \\
1 \times \text { payload } \\
\text { Oil } \\
\mathrm{O}_{1} \text { Manisa } \\
?\left(18 \mathrm{PD}_{50}\right) \\
10 \times \text { payload }\end{array}$ & $\begin{array}{c}\text { Semi-heterologous } \\
\text { direct contact with } 5 \\
\text { infectious cattle for } 5 \\
\text { days }\end{array}$ & $0 / 10$ & & & & & & & $14 / 20$ & & & & $20 / 20$ & {$[22,23]$} \\
\hline
\end{tabular}




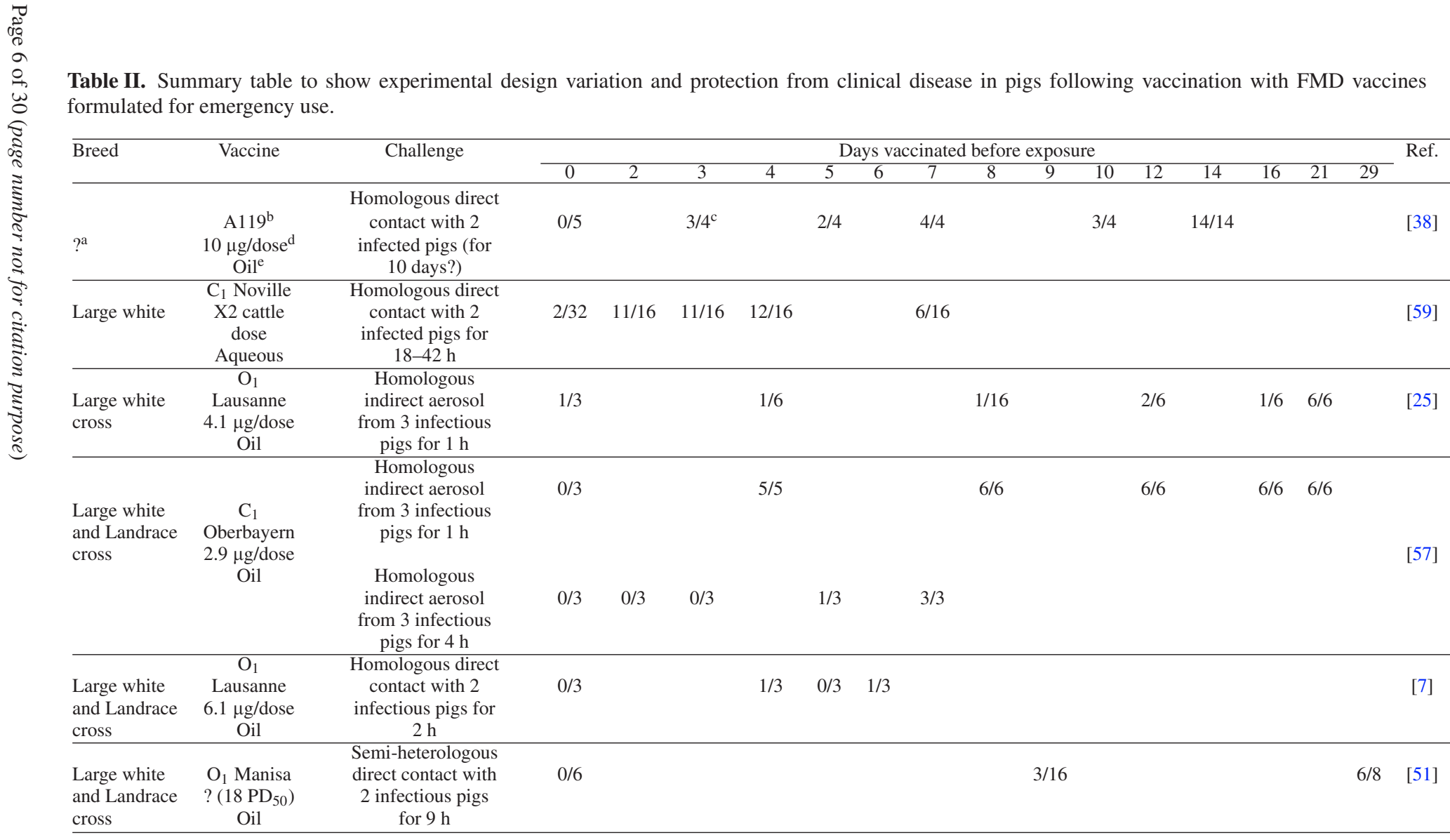

${ }^{\mathrm{a}}$ Not specified, ${ }^{\mathrm{b}}$ vaccine serotype, ${ }^{\mathrm{c}}$ number protected/total number in group,${ }^{\mathrm{d}}$ concentration of antigen/dose, ${ }^{\mathrm{e}}$ vaccine type. 
Table III. Summary table to show experimental design variation and protection from clinical disease (lesions) in sheep following vaccination with FMD vaccines formulated for emergency use.

\begin{tabular}{|c|c|c|c|c|c|c|c|c|c|c|c|c|}
\hline \multirow[t]{2}{*}{ Breed } & \multirow[t]{2}{*}{ Vaccine } & \multirow[t]{2}{*}{ Challenge } & \multicolumn{9}{|c|}{ Days vaccinated before exposure } & \multirow[t]{2}{*}{ Ref. } \\
\hline & & & 0 & 3 & 4 & 5 & 6 & 7 & 10 & 11 & 14 & \\
\hline \multirow{7}{*}{ Crossbred } & $\mathrm{O}_{1}$ BFS $1860^{\mathrm{a}}$ & & & & & & & & & & & \\
\hline & $19.8 \mu \mathrm{g} / \mathrm{dose}^{\mathrm{c}}$ & & & & & & & $4 / 4^{b}$ & & & & \\
\hline & Aqueous $^{\mathrm{d}}$ & Homologous indirect & & & & & & & & & & \\
\hline & & aerosol from 4 infectious & $0 / 4$ & & & & & & & & & [36] \\
\hline & $\mathrm{O}_{1}$ BFS 1860 & pigs for $2 \mathrm{~h}$ & & & & & & & & & & \\
\hline & $9.9 \mu \mathrm{g} / \mathrm{dose}$ & & & & & & & & & & & \\
\hline & Aqueous & & & & & & & $3 / 4$ & & & & \\
\hline \multirow{12}{*}{$\begin{array}{l}\text { Polled Dorset } \\
\text { Horn }\end{array}$} & $\mathrm{O}_{1}$ Lausanne & & & & & & & & & & & \multirow{12}{*}{ [19] } \\
\hline & $3.05 \mu \mathrm{g} / \mathrm{dose}$ & & & $3 / 3$ & $3 / 3$ & & $3 / 3$ & & $3 / 3$ & & & \\
\hline & Aqueous & Homologous indirect & & & & & & & & & & \\
\hline & & aerosol from 3 infectious & $1 / 4$ & & & & & & & & & \\
\hline & $\mathrm{O}_{1}$ Lausanne & pigs for $2 \mathrm{~h}$ & & & & & & & & & & \\
\hline & $3.05 \mu \mathrm{g} / \mathrm{dose}$ & & & $3 / 3$ & $3 / 3$ & & $3 / 3$ & & $3 / 3$ & & & \\
\hline & Oil & & & & & & & & & & & \\
\hline & & & & & & & & & & & & \\
\hline & $\begin{array}{l}\text { Asia } 1 \text { India 8/79 } \\
2.25 \mu \mathrm{g} / \text { dose }\end{array}$ & $\begin{array}{c}\text { Homologous indirect } \\
\text { aerosol from } 3 \text { infectious }\end{array}$ & $0 / 3$ & $3 / 3$ & $3 / 3$ & & $3 / 3$ & & $3 / 3$ & & & \\
\hline & Oil & pigs for $4 \mathrm{~h}$ & & & & & & & & & & \\
\hline & $\mathrm{C}_{1}$ Oberbayern & Homologous indirect & & & & & & & & & & \\
\hline & $\begin{array}{c}1.4 \mu \mathrm{g} / \mathrm{dose} \\
\text { Aqueous }\end{array}$ & $\begin{array}{c}\text { aerosol from } 3 \text { infectious } \\
\text { pigs for } 4 \mathrm{~h}\end{array}$ & $1 / 3$ & & $3 / 3$ & $3 / 3$ & & $3 / 3$ & & $3 / 3$ & & \\
\hline Polled Dorset & $\mathrm{C}_{1}$ Oberbayern & Homologous indirect & & & & & & & & & & \\
\hline Horn & $\begin{array}{c}1.4 \mu \mathrm{g} / \mathrm{dose} \\
\text { Oil }\end{array}$ & $\begin{array}{c}\text { aerosol from } 3 \text { infectious } \\
\text { pigs for } 4 \mathrm{~h}\end{array}$ & $0 / 3$ & & $3 / 3$ & $3 / 3$ & & $3 / 3$ & & $3 / 3$ & & See footnote 2 \\
\hline Polled Dorset & $\mathrm{O}_{1}$ Lausanne & Homologous indirect & & & & & & & & & & \\
\hline Horn & $\begin{array}{l}3.05 \mu \mathrm{g} / \mathrm{dose} \\
\text { Aqueous }\end{array}$ & $\begin{array}{c}\text { aerosol from } 2 \text { infectious } \\
\text { pigs for } 4 \mathrm{~h}\end{array}$ & $0 / 7$ & & & & & & & & $7 / 7$ & [10] \\
\hline & $\mathrm{O}_{1}$ Manisa & Semi-heterologous & & & & & & & & & & \\
\hline Polled Dorset & ? (18 $\mathrm{PD}_{50}$ for & indirect aerosol from 3 & $0 / 8$ & & $9 / 10$ & & & & $8 / 10$ & & & [52] \\
\hline Horn & cattle) & infectious pigs for $9 \mathrm{~h}$ & & & & & & & & & & \\
\hline
\end{tabular}


during the 1990's, using vaccines prepared from antigens held as part of the emergency reserve in the International FMD Vaccine Bank (IVB) at the Institute for Animal Health, Pirbright Laboratory, and an indirect aerosol challenge from infected pigs, confirmed that higher potency vaccines could protect cattle and pigs from clinical disease at 2 (strain Asia 1 India) to 4 (strains $\mathrm{O}_{1}$ Lausanne and $\mathrm{C}_{1}$ Oberbayern) days and 4 (strain $\mathrm{C}_{1}$ Oberbayern) days post vaccination respectively (Tabs. I and II) $[25,57]^{1}$. At the time of these later studies it became apparent that sheep and other small ruminants were involved in most of the outbreaks in and around the EU member states [5] and that in an emergency situation it might be necessary to also vaccinate these species. Since historically, sheep and goats were not normally included in vaccination programs, more information on vaccine efficacy was required in these species. Hence a series of experiments using emergency monovalent FMD vaccines, incorporating either serotype $\mathrm{O}_{1}$ Lausanne, Asia 1 India and $\mathrm{C}_{1}$ Oberbayern from the IVB reserve, were undertaken to investigate early protection in sheep $[19]^{2}$. Since sheep are generally less prone to the clinical manifestations of FMD, the absence of viraemia was also considered as an indicator of protection. It was concluded that emergency vaccines, previously shown to be effective in eliciting early protection in cattle and pigs, could perform equally well in sheep, as they were protected as

${ }^{1}$ Salt J.S., Williams L., Statham R., Barnett P.V., Further studies on the rate of development of protection in cattle given emergency vaccination against FMD, Rep. Session Res. Group Standing Techn. Comm. Eur. Comm. Contr. FMD, Moeldling, Denmark, FAO, Rome, 1995, Appendix 17, pp. 90-97.

${ }^{2}$ Cox S.J., Dani P., Salt J.S., Barnett P.V., Effect of emergency vaccines on local virus replication and virus persistence in sheep using two different adjuvant formulations, Rep. Session Res. Group Standing Techn. Comm. Eur. Comm. Contr. FMD, Pirbright, UK, FAO, Rome, 1998, Appendix 17, pp. 139-143. early as 3 (strain $\mathrm{O}_{1}$ Lausanne) or 4 days post vaccination (strains Asia 1 India and $\mathrm{C}_{1}$ Oberbayern) (Tab. III). Protection was further demonstrated by a later experiment using larger groups of sheep which had been vaccinated 14 days before FMDV challenge with $\mathrm{O}_{1}$ Lausanne (Tab. III) [10]. More recent work using sheep that had been vaccinated 10 and 4 days prior to a semi-heterologous, $9 \mathrm{~h}$ indirect aerosol challenge from pigs, confirmed protection against clinical disease but showed that not all animals were protected from generalization of FMD, as some became viraemic (Tab. III) [52].

\subsection{Vaccine studies demonstrating protection against clinical disease using direct contact challenge}

The previously mentioned studies with emergency vaccines, prepared from antigen concentrates held over liquid nitrogen, have nearly all involved indirect aerosol challenge, to simulate a situation in which infected premises could infect a neighbouring farm through windborne spread. This along with indirect spread via fomites are thought to be the most likely methods for the spread of FMDV between farms once movement restrictions are in place, but fomite spread is difficult to model experimentally. Suppressive vaccination, as used in the Netherlands during 2001, where emergency vaccination is applied around and within the disease foci as a supplementary control measure to further dampen down virus excretion, has received more consideration in recent years. A number of experiments have examined the efficacy of emergency vaccines against direct contact challenge, as if vaccination is applied within an infected area, there could be the likelihood that some animals may already be incubating disease on a farm, and therefore be able to directly challenge other animals. An initial study [7] using an $\mathrm{O}_{1}$ Lausanne oil formulated vaccine, in which groups of three pigs were immunized at 6,5 and 4 days prior to a direct homologous FMDV challenge from two infected pigs for $2 \mathrm{~h}$, showed that all but one pig in the four day group and one in the six 
day group developed clinical disease (Tab. II). More recently, published work using a larger number of pigs, investigating the efficacy of emergency vaccines against a more severe semi-heterologous direct contact challenge of $9 \mathrm{~h}$, has shown that protection from clinical disease is difficult to achieve at 10 days post vaccination, as only $19 \%$ of the group were protected (Tab. II) [51]. However, protection was greatly improved by extending the time period between vaccination and challenge to 29 days, where $75 \%$ remained healthy. Likewise, similar work with vaccinated cattle, using a five day direct contact challenge from five infected cattle, has shown that following a 21 day vaccine-to-challenge interval, with either single strength or $10 \times$ antigen payload, all cattle were protected from disease (Tab. I) $[21,22]$. However, when a shorter time period of 10 days between vaccination and challenge was used, protection was only achieved in $70-75 \%$ of the group, although disease in the unprotected animals was less severe than in unvaccinated controls receiving the same challenge [23]. As far as the authors are aware, no similar experiments have been carried out using sheep.

\section{EFFICACY OF FMD VACCINES TO PROTECT AGAINST SUB-CLINICAL INFECTION, REDUCE VIRUS EXCRETION AND PERSISTENCE IN ANIMALS EXPERIMENTALLY CHALLENGED WITH UNVACCINATED FMDV INFECTED DONOR ANIMALS}

\subsection{Prevention of sub-clinical infection, virus excretion and persistence in cattle}

Clearly it is advantageous if a vaccine protects not only against clinical disease but also sub-clinical infection, as the likelihood of disease transmission will thereby be reduced or indeed eliminated. Results from early studies frequently indicate that FMD vaccines which are able to protect from clinical disease are unable to provide sterile immunity (i.e., prevent sub-clinical infection) although there are occasions, periodically or consistently, when no virus is recovered from some animals $[29,42,60,62]^{3}$; although it should be emphasized that animals were sometimes only sampled once or twice during these studies. Further, it was not fully investigated in these experiments whether increasing the antigen content in the vaccine or the time period between vaccination and challenge could further reduce sub-clinical infection. The series of previously described experiments in cattle carried out by the IVB in the 1990's [25], using vaccines prepared from the antigens held in its emergency reserve was undertaken to address these issues more comprehensively by examining oropharyngeal fluid samples collected by probang cup [63] and the data from these experiments are summarised in Table IV. Studies with $\mathrm{O}_{1}$ Lausanne suggested that the shorter the period between vaccination and challenge the more likely that virus was recovered, although virus was recovered from all animals, in all groups, on at least one occasion. Previously, it was concluded that use of the aqueous vaccine formulation appeared to be more effective at reducing the levels of virus recovery [9], but on re-examination of the data for this review, the variability at different time points for both aqueous and oil adjuvants and the small group size suggests that this conclusion was not justified. Re-vaccination of the same animals, approximately four months later, with $\mathrm{C}_{1}$ Oberbayern resulted in far fewer animals locally replicating virus, regardless of adjuvant. This may have been related to a difference in the strains ability to establish a sub-clinical infection, and/or higher potency of the $\mathrm{C}_{1}$ Oberbayern vaccine, and/or the result of pre-existing immunity to the previous vaccine. Hence, a comparison with the $\mathrm{O}_{1}$ Lausanne data is not really possible. A further study was performed using Asia 1 India, in which cattle were vaccinated at intervals between 2 and 12 days prior to challenge. The results from this experiment were similar to those of the earlier $\mathrm{O}_{1}$ Lausanne vaccination

\footnotetext{
${ }^{3}$ Garland A.J.M., The inhibitory activity of secretions in cattle against foot-and-mouth disease virus, Ph.D. thesis, University of London, UK, 1974.
} 


\begin{tabular}{|c|c|c|c|c|c|c|c|c|c|c|c|c|c|c|}
\hline \multirow[t]{2}{*}{ Vaccine } & \multirow[t]{2}{*}{ Challenge } & \multirow{2}{*}{$\begin{array}{c}\text { Days } \\
\text { vaccinated } \\
\text { before exposure }\end{array}$} & \multicolumn{10}{|c|}{$\begin{array}{l}\text { Virus isolation (or viral RNA recovery) from oropharyngeal } \\
\text { fluids weeks post challenge }\end{array}$} & \multirow[t]{2}{*}{$\mathrm{NSAB}^{\mathrm{a}}$} & \multirow[t]{2}{*}{ Ref. } \\
\hline & & & 1 & 2 & 3 & 4 & 5 & 6 & 7 & 8 & 9 & 10 & & \\
\hline & & 21 & $3 / 3^{b}$ & $3 / 3$ & $3 / 3$ & $1 / 3$ & $1 / 3$ & $0 / 3$ & $3 / 3$ & $1 / 2$ & $3 / 3$ & $2 / 3$ & & \multirow{12}{*}[25]{} \\
\hline $\mathrm{O}_{1}$ Lausanne & & 16 & $0 / 2$ & $3 / 3$ & $1 / 3$ & $1 / 3$ & $0 / 3$ & $0 / 3$ & $0 / 3$ & $0 / 3$ & $0 / 3$ & $0 / 3$ & & \\
\hline $4.1 \mu \mathrm{g} /$ dose & & 12 & $3 / 3$ & $2 / 2$ & $3 / 3$ & $2 / 3$ & $2 / 3$ & $1 / 2$ & $1 / 3$ & $1 / 3$ & $2 / 3$ & $2 / 3$ & & \\
\hline \multirow[t]{4}{*}{ Oil } & & 8 & $2 / 3$ & $3 / 3$ & $3 / 3$ & $1 / 3$ & $3 / 3$ & $1 / 3$ & $2 / 3$ & $3 / 3$ & $3 / 3$ & $3 / 3$ & & \\
\hline & & 4 & $2 / 2$ & $2 / 2$ & $2 / 2$ & $2 / 2$ & $2 / 2$ & $2 / 2$ & $2 / 2$ & $0 / 2$ & $2 / 2$ & $2 / 2$ & & \\
\hline & Homologous indirect aerosol from & & & & & & & & & & & & & \\
\hline & 3 infectious pigs for $1 \mathrm{~h}$ & 21 & $0 / 2$ & $1 / 2$ & $2 / 2$ & $0 / 2$ & $0 / 2$ & $0 / 2$ & $0 / 2$ & $0 / 2$ & $0 / 2$ & $1 / 2$ & & \\
\hline $\mathrm{O}_{1}$ Lausanne & & 16 & $2 / 3$ & $3 / 3$ & $3 / 3$ & $2 / 3$ & $3 / 3$ & $1 / 2$ & $1 / 3$ & $1 / 3$ & $2 / 3$ & $1 / 3$ & & \\
\hline $4.1 \mu \mathrm{g} / \mathrm{dose}$ & & 12 & $1 / 3$ & $3 / 3$ & $3 / 3$ & $1 / 3$ & $1 / 3$ & $1 / 3$ & $3 / 3$ & $1 / 3$ & $1 / 3$ & $1 / 3$ & & \\
\hline \multirow[t]{3}{*}{ Aqueous } & & 8 & $2 / 3$ & $3 / 3$ & $3 / 3$ & $2 / 3$ & $2 / 3$ & $2 / 3$ & $1 / 2$ & $2 / 3$ & $2 / 3$ & $2 / 3$ & & \\
\hline & & 4 & $1 / 2$ & $1 / 1$ & $2 / 2$ & $1 / 2$ & $1 / 2$ & $1 / 2$ & $1 / 2$ & $0 / 0$ & $1 / 2$ & $1 / 1$ & & \\
\hline & & 0 & $1 / 1$ & $2 / 2$ & $2 / 2$ & $2 / 2$ & $2 / 2$ & $2 / 2$ & $2 / 2$ & $2 / 2$ & $2 / 2$ & $1 / 1$ & & \\
\hline & & 21 & $0 / 3$ & $0 / 3$ & $0 / 3$ & $0 / 3$ & $0 / 3$ & $0 / 3$ & $0 / 3$ & $1 / 3$ & $0 / 3$ & $0 / 3$ & & \multirow{12}{*}{ [25] } \\
\hline${ }^{\mathrm{c}} \mathrm{C}_{1}$ Oberbayern & & 16 & $0 / 3$ & $0 / 3$ & $0 / 3$ & $0 / 3$ & $0 / 3$ & $0 / 3$ & $0 / 3$ & $0 / 3$ & $0 / 3$ & $0 / 3$ & & \\
\hline $1.9 \mu \mathrm{g} / \mathrm{dose}$ & & 12 & $1 / 3$ & $1 / 3$ & $3 / 3$ & $1 / 3$ & $0 / 3$ & $0 / 3$ & $0 / 2$ & $0 / 2$ & $0 / 2$ & $0 / 2$ & & \\
\hline oil & & 8 & $1 / 3$ & $0 / 3$ & $1 / 3$ & $0 / 3$ & $0 / 3$ & $0 / 3$ & $1 / 3$ & $1 / 3$ & $0 / 3$ & $0 / 3$ & & \\
\hline & & 4 & $0 / 2$ & $0 / 2$ & $1 / 2$ & $0 / 2$ & $0 / 2$ & $0 / 2$ & $0 / 2$ & $0 / 2$ & $0 / 1$ & $0 / 2$ & & \\
\hline & Homologous indirect aerosol from & & & & & & & & & & & & & \\
\hline & 3 infectious pigs for $1 \mathrm{~h}$ & 21 & $1 / 3$ & $0 / 3$ & $0 / 3$ & $0 / 3$ & $0 / 3$ & $0 / 3$ & $0 / 3$ & $0 / 1$ & $0 / 3$ & $0 / 3$ & & \\
\hline${ }^{\mathrm{d}} \mathrm{C}_{1}$ Oberbayern & & 16 & $0 / 3$ & $0 / 2$ & $0 / 2$ & $0 / 2$ & $0 / 2$ & $0 / 2$ & $0 / 2$ & $0 / 2$ & $0 / 2$ & $0 / 2$ & & \\
\hline $1.9 \mu \mathrm{g} /$ dose & & 12 & $0 / 3$ & $0 / 3$ & $0 / 3$ & $0 / 3$ & $0 / 3$ & $0 / 3$ & $0 / 3$ & $0 / 3$ & $0 / 3$ & $0 / 3$ & & \\
\hline \multirow[t]{3}{*}{ Aqueous } & & 8 & $0 / 3$ & $0 / 3$ & $0 / 3$ & $0 / 3$ & $0 / 3$ & $0 / 3$ & $0 / 3$ & $0 / 3$ & $0 / 3$ & $0 / 3$ & & \\
\hline & & 4 & $0 / 2$ & $0 / 2$ & $1 / 2$ & $1 / 2$ & $1 / 2$ & $0 / 2$ & $0 / 2$ & $0 / 2$ & $0 / 2$ & $0 / 2$ & & \\
\hline & & 0 & $1 / 2$ & $2 / 2$ & $2 / 2$ & $2 / 2$ & $2 / 2$ & $0 / 2$ & $1 / 2$ & $0 / 2$ & $1 / 2$ & $0 / 2$ & & \\
\hline \multirow{5}{*}{$\begin{array}{l}\text { Asia } 1 \text { India } 8 / 79 \\
4.8 \mu \mathrm{g} / \text { dose } \\
\text { Oil }\end{array}$} & & 12 & NA & & & $1 / 2$ & & & & & & & & \multirow{5}{*}{$\begin{array}{c}\text { See } \\
\text { footnote } 1\end{array}$} \\
\hline & Homologous indirect aerosol from & 8 & $3 / 3$ & & & $2 / 3$ & & & & & & & & \\
\hline & 3 infectious pigs for $1 \mathrm{~h}$ & 4 & $2 / 2$ & & & $2 / 2$ & & & & & & & & \\
\hline & & 3 & NA & & & $1 / 3$ & & & & & & & & \\
\hline & & 2 & $3 / 3$ & & & $3 / 3$ & & & & & & & & \\
\hline
\end{tabular}


Table IV. Continued.

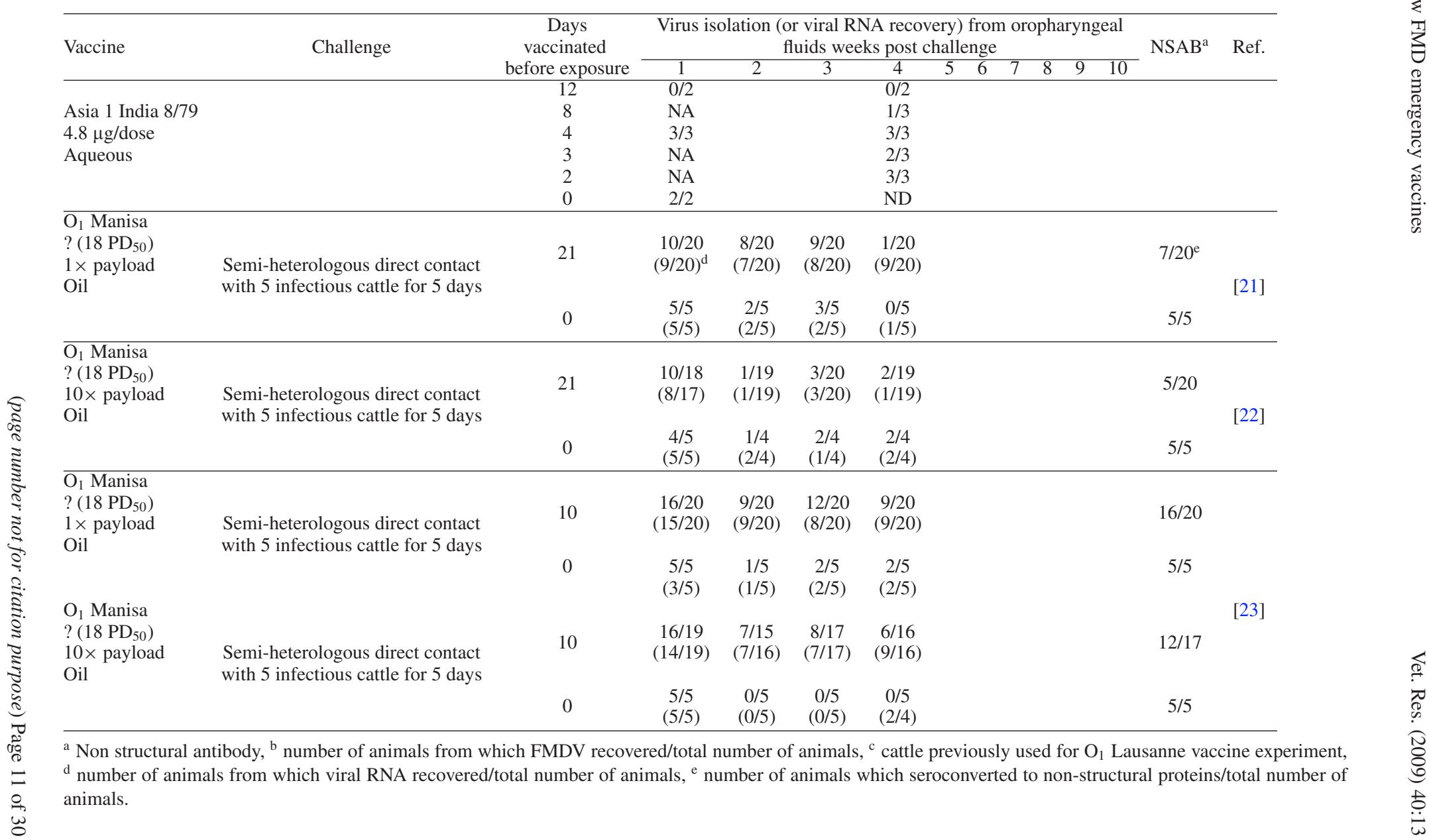


experiment, as virus was recovered from all groups of vaccinated cattle (except the 12 days pre-challenge aqueous group). This study also supported the previous observation from the $\mathrm{O}_{1}$ Lausanne study, that the longer the period between vaccination and challenge the less likely virus was recovered and fewer the animals that become persistently infected. More recent studies at IAH Pirbright in cattle, to assess the efficacy of a high potency $\mathrm{O}_{1}$ Manisa oil formulated vaccine applied 21 days prior to a direct contact challenge from infected cattle against both clinical disease and sub-clinical infection using larger group size, have shown more conclusively that vaccination greatly reduces the amount of virus recovered from vaccinated cattle as compared to unvaccinated cattle, both in terms of numbers of animals from which virus was recovered and the quantity of virus recovered from infected animals [21]. This was particularly true during the early post-exposure period during which 100-1000 times more viral RNA was recovered from unvaccinated cattle. Increasing the antigen payload of this vaccine ten-fold resulted in even less virus recovery and less persistently infected animals (if recovery of viral RNA was also used as a measure of persistence [22]). These studies have recently been repeated with an interval of 10 days between immunization and challenge, and although no significant difference was identified between vaccinated and unvaccinated cattle with regard to the numbers of cattle sub-clinically infected, a difference in actual quantity of virus recovered shortly after challenge was still apparent, with 10-150 times less viral RNA recovered from a vaccinated animal [23].

Data from these recent $\mathrm{O}_{1}$ Manisa cattle experiments [21-23] are also summarized in Table IV, including non-structural antibody results from each of these experiments, in order to allow comparison with the earlier work. Techniques for analyzing samples and determining status of individual cattle have moved on since this early work, and the use of quantitative RT-PCR for estimating levels of viral replication and ELISA's for nonstructural antibody seroconversion allow more accurate assessment of vaccine efficacy than in the past with regard to sub-clinical infection. For example, it appears from the $\mathrm{O}_{1}$ Manisa cattle work [21-23], that non-structural antibody development correlates with the extent of virus replication and thus offers a reliable alternative to virus isolation from oropharyngeal fluid, which can provide inconsistent results, both from a single sample or over a set of time course samples from an individual animal. The availability of quantitative RT-PCR, which is more rapid and less labour intensive than cell culture titration, also permits more precise discrimination between levels of virus replication in individual and groups of animals [21-23]. Despite the direct challenge being more severe than used previously, the results indicate that vaccination will reduce the number of sub-clinically infected animals.

Clinically affected and sub-clinically infected animals have the potential to become persistently infected, and although the role of persistence in the epidemiology of FMD has not been proven, any reduction in both, as a result of vaccination, is likely to reduce the number of persistently infected animals and the subsequent possibility of transmission from them. Since clinically diseased animals are more likely to be recognized and removed, vaccinated sub-clinically infected animals potentially pose more of a problem. The $\mathrm{O}_{1}$ Manisa experiments have monitored cattle up to and beyond 28 days post challenge to assess the effect of emergency vaccination on reducing persistence [21-23]. The four week post challenge data in Table IV shows the number of persistently infected cattle in each experiment. Although a trend was identified from the early IVB cattle work $[25]^{1}$ that less animals became persistently infected the longer the period between vaccination and challenge, the small group sizes and variability of data makes this difficult to substantiate. The virus isolation results from the more recent studies [21-23] in which challenge occurred at 21 and 10 days post immunization do appear to confirm this trend, as FMDV was recovered from $5 \%$ of cattle vaccinated 21 days before challenge and $50 \%$ of cattle vaccinated 10 days before challenge, using

Page 12 of 30 (page number not for citation purpose) 
single strength vaccine. Similar differences were also seen for the 10-fold antigen payload vaccine. However, if virus isolation and/or viral RNA recovery are used collectively as an indicator of persistence, a slightly different picture emerges, and a lower level of persistence is then only seen in the cattle receiving a 10-fold antigen payload vaccine 21 days before challenge. Although the observed levels of persistence are toward the upper levels quoted in FMD literature, the true level of persistence from a severe direct contact challenge could be as high as $75 \%$ of infected, vaccinated animals. It might be extrapolated, however, that a less severe challenge will result in a lower level of persistence and it is still to be resolved whether detection of viral RNA without equivalent detection of live virus at 28 days post challenge and beyond should be considered as evidence of persistence.

\subsection{Prevention of sub-clinical infection, virus replication and persistence in sheep}

A single experiment in which sheep were vaccinated with large doses of a monovalent type O BFS 1860 vaccine followed by indirect contact exposure to infectious pigs for $2 \mathrm{~h}$ showed that local virus replication in the oropharynx was not prevented [36]. However, since the fully formulated vaccine used in this study had been stored at $4{ }^{\circ} \mathrm{C}$ for 10 months before use it might have deteriorated such that efficacy would not have been as good as that conferred by newly prepared vaccine. More recent early protection studies in sheep [19] $]^{2}$, using freshly prepared vaccine, afforded the opportunity to investigate the effect of aqueous and oil formulated emergency vaccines on sub-clinical infection [19] and results from these experiments are summarized in Table V. Both oil and aqueous monovalent formulations of $\mathrm{O}_{1}$ Lausanne and $\mathrm{C}_{1}$ Oberbayern seemed to reduce the frequency of sub-clinical infection when monitored up to 28 days post challenge. All sheep vaccinated at least 7 days before challenge remained free of virus in the oesophageal-pharyngeal tract throughout the trials. However, in the study, using oil adjuvanted Asia 1 India vaccine [19], virus was recovered from sheep vaccinated 6 and 10 days before challenge, which, along with the cattle data above, suggests that it might be more difficult to protect against sub-clinical infection by this serotype. The data generated from the use of both $\mathrm{O}_{1}$ Lausanne and $\mathrm{C}_{1}$ Oberbayern aqueous and oil formulated vaccines partly supported the previous observations in cattle that the earlier the vaccine is administered before challenge, the more effectively the sub-clinical infection will be prevented. As observed for cattle, there was also no tendency toward either vaccine formulation being more effective than the other at reducing subclinical infection. In another study [52], in which sheep were vaccinated with an $\mathrm{O}_{1}$ Manisa oil vaccine, either 10 or 4 days before challenge with $\mathrm{O}_{1} \mathrm{UKG}$, the notion that vaccination considerably reduces subclinical infection is also supported (Tab. V). This study also showed that seroconversion to nonstructural proteins was weak and transient in sheep in which virus replication was of low level or short duration and that the earlier the vaccine is administered before challenge the more effectively virus replication is reduced [52]. In all the experiments reviewed, viral persistence (at 4 weeks or beyond) was less in the vaccinated animals compared to the unvaccinated sheep.

\subsection{Influence of antigen payload on sub-clinical infection, virus replication and persistence in sheep}

Antigen concentration (payload) per vaccine dose can be increased in order to achieve higher potency vaccine. Since potency tests measure protection in terms of their ability to prevent generalization of disease from the site of inoculation and do not consider sub-clinical infection, there was little data available on whether increasing antigen payload can decrease local virus replication. An experiment carried out in sheep, was designed specifically to investigate the effect of antigen payload on local virus replication. Single administrations of either a high, medium or low antigen payload $\mathrm{O}_{1}$ Lausanne vaccine 


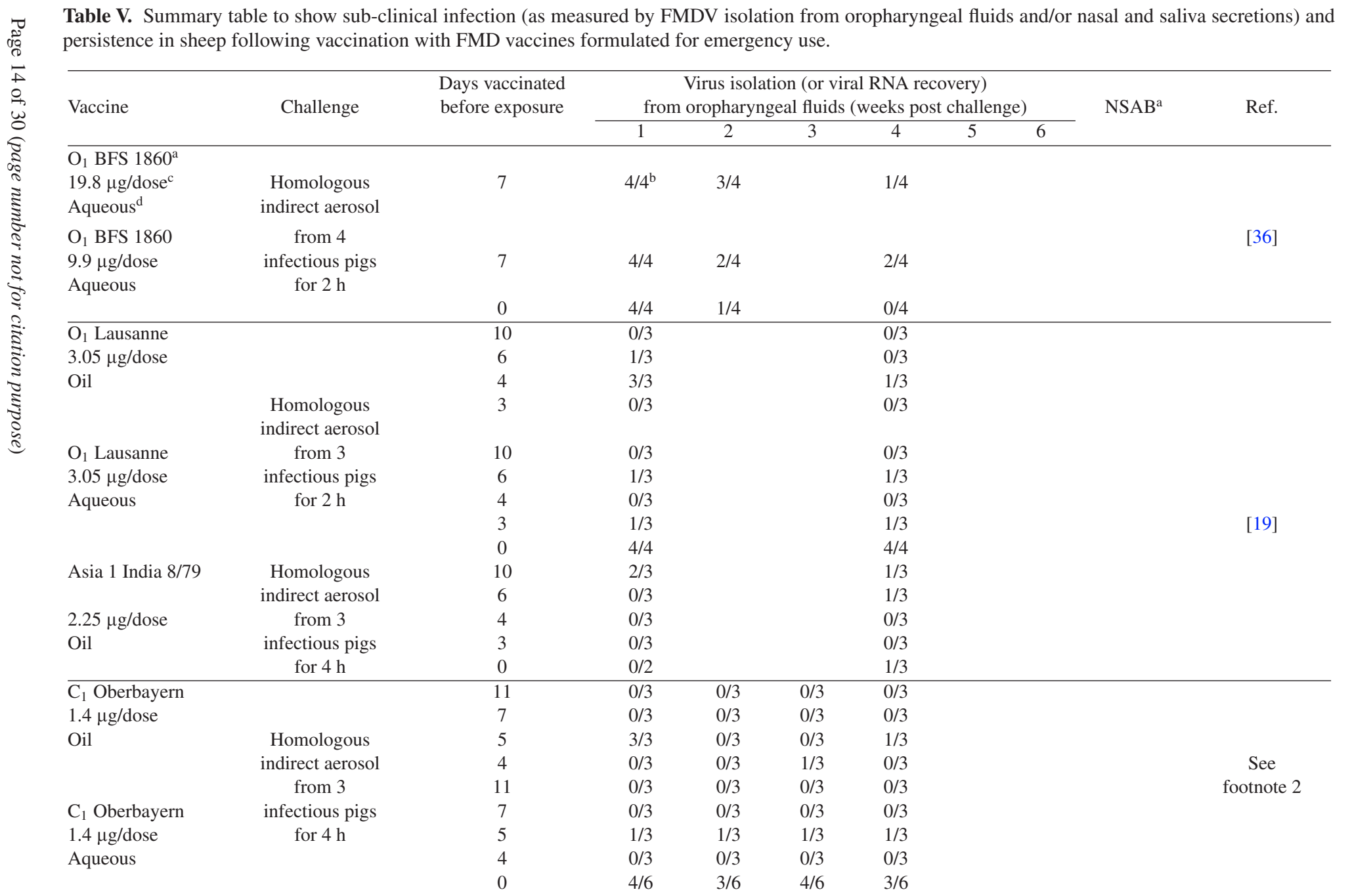


Table V. Continued.

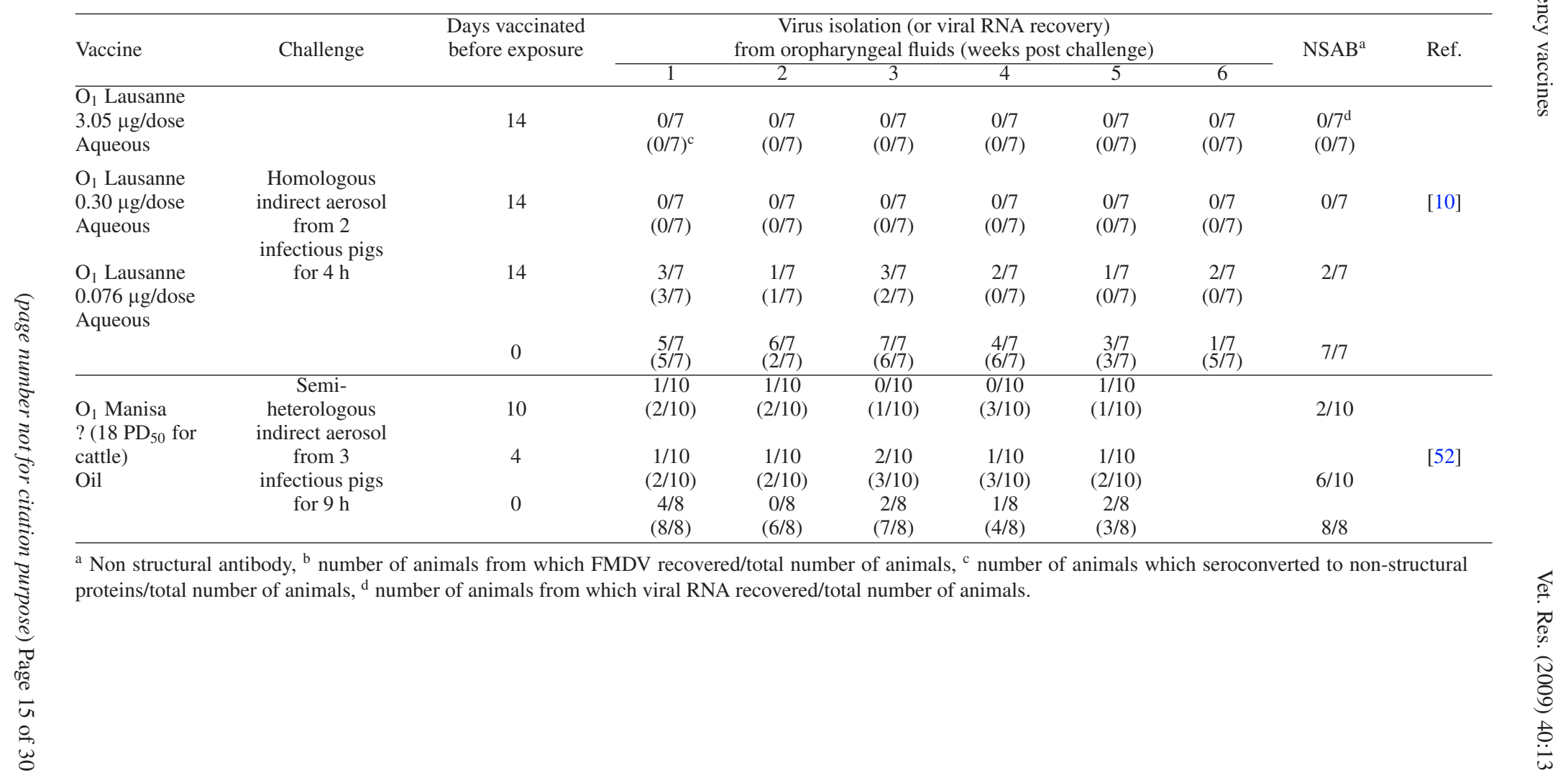


were assessed for their ability to protect groups of seven sheep and reduce local virus replication and excretion from the oropharynx following indirect aerosol challenge at 14 days post immunization [10]. Seven unvaccinated sheep in this experiment showed signs of clinical FMD, whereas all the vaccinated sheep, regardless of antigen payload, were protected against clinical disease and development of viraemia. Virological and serological results confirmed that there had been no local virus replication in the oropharynx of the sheep from the highest antigen payload vaccine group in contrast to moderate or substantial virus replication in the oropharynx of the lowest payload or unvaccinated group of sheep respectively (Tab. V). Sero-conversion against non-structural proteins was also evident in the lowest antigen payload and unvaccinated groups. This was the first experiment to clearly show that higher antigen payload vaccines are capable of inhibiting local virus replication and the consequential persistent infection and carrier state in this target species. The vaccines showed no evidence of promoting a local mucosal antibody response at the time of challenge but were capable of stimulating a systemic interferon gamma response, the level of which appeared to be related to antigen payload. The magnitude of response and number of animals having measurable levels of interferon gamma certainly decreased as antigen payload was reduced. It was concluded that this systemic interferon gamma response could be a useful indicator of the ability of an FMD vaccine to inhibit local virus replication, warranting further investigation.

\subsection{Prevention of sub-clinical infection and virus excretion in pigs}

Less work has been carried out in pigs to examine the effect of vaccination on local virus replication in the absence of clinical signs (sub-clinical infection), most likely because they are not known to become persistently infected carriers. However, since pigs are recognized as 'amplifiers' of FMDV [58] any reduction in local virus replication at the acute phase, would be beneficial in the control of the disease. For the purpose of this section virus excretion is taken as being representative of local virus replication having occurred.

A significant reduction in airborne virus recovery from groups of pigs, as measured by sampling the air of looseboxes, was achieved when they were vaccinated prior to challenge, although a single immunization did not prevent clinical disease in most pigs [60]. Likewise, Salt et al. [57] made no attempt to evaluate sub-clinical infection in individual pigs following vaccination with high potency vaccine, preferring to measure levels of excretion per group of pigs in isolation boxes and assess transmission to naïve incontacts (see Sect. 4). It was concluded that protective immunization resulted in reduced virus excretion. An experiment carried out by Davidson ${ }^{4}$, the first to assess airborne recovery from individual pigs, confirmed that vaccination with a high potency oil adjuvanted $\mathrm{O}_{1}$ Lausanne vaccine, at either 7 or 21 days prior to direct contact with infected pigs for $16 \mathrm{~h}$, could result in no virus recovery from some animals (after removal of infected donor animals) (Tab. VI) but concluded that the vaccine could not effectively prevent local virus replication and airborne virus emissions in all situations. However, it was also noted that after the first $24 \mathrm{~h}$, the highest airborne recovery from sub-clinically infected pigs was significantly lower than peak recoveries from diseased pigs $(P<0.05)$. A further study was designed to investigate protection from direct contact challenge 4, 5 and 6 days post vaccination. This experiment considered detection of FMDV from both nasal swab material of the individual animals and via HEPEs buffered Eagles medium in air exposed Petri dishes within each animal box housing the different vaccination groups. This showed that a high potency $\mathrm{O}_{1}$ Lausanne vaccine was unable to prevent local virus replication at such short intervals between vaccination and challenge [7]. However, the excreted virus titres determined from each isolation box were

\footnotetext{
${ }^{4}$ Davidson F.L., Alternative strategies for footand-mouth disease control in pigs, Ph.D. thesis, University of Hertfordshire, UK, 1997.
} 
Table VI. Airborne virus recovery from vaccinated pigs following direct contact challenge with infected pigs.

\begin{tabular}{lcccccccccc}
\hline $\begin{array}{l}\text { Animal } \\
\text { ref. }\end{array}$ & $\begin{array}{l}\text { Days vaccinated } \\
\text { before exposure }\end{array}$ & Disease & \multicolumn{4}{c}{ Airborne virus recovery $\left(\log _{10}\right.$ TCID $_{50}$ recovered in 15 min) } \\
\hline SP 20 & 7 & No & 5.5 & 2.9 & Neg & Neg & Neg & Neg & Neg & Neg \\
SP 21 & 7 & No & 4.2 & 2.9 & 2.4 & Neg & Neg & Neg & Neg & Neg \\
SP 76 & 7 & No & 3.7 & 3.7 & 1.9 & Neg & Neg & 2.2 & Neg & Neg \\
SP 77 & 7 & No & 3.6 & 2.4 & Neg & Neg & 2.0 & 2.2 & Neg & Neg \\
SP 33 & 21 & No & 3.4 & Neg & Neg & Neg & Neg & Neg & Neg & Neg \\
SP 35 & 21 & No & 3.9 & 2.4 & Neg & 2.2 & 2.2 & 2.0 & 1.9 & Neg \\
SP 78 & 21 & Yes & 4.5 & Neg & Neg & 4.2 & 4.7 & 3.9 & Neg & Neg \\
SP 79 & 21 & No & 3.7 & 2.4 & Neg & Neg & Neg & Neg & Neg & Neg \\
SP 67 & 0 & No & 3.7 & 2.2 & 2.2 & 2.2 & 2.2 & 2.2 & 1.9 & 1.9 \\
SP 80 & 0 & Yes & 3.9 & 2.4 & 1.9 & 4.7 & 5.9 & Died & - & - \\
\hline
\end{tabular}

The shaded area denotes the presence of the donor pig.

reduced by $90-98 \%$ when compared with the box holding the infected non-vaccinated control animals. A more recent study [30], designed more specifically to investigate within pen transmission (see Sect. 4), demonstrated that local virus replication, as measured by virus recovery from oropharyngeal fluid collected by cotton mouth swabs, could be prevented in pigs vaccinated 14 days prior to infection, but not in those vaccinated 7 days prior to infection. Another recent study [51], however, using a semi-heterologous, direct contact challenge at 10 and 29 days post vaccination showed that although high potency vaccine was unable to prevent sub-clinical infection, as all vaccinated pigs appeared to have become infected to some degree, the vaccine was able to reduce virus replication and excretion, which could be correlated to the severity of clinical disease.

\section{EFFECT OF FMD VACCINES ON PREVENTING FMDV TRANSMISSION TO NAIVE AND VACCINATED ANIMALS FROM EXPERIMENTALLY CHALLENGED ANIMALS}

\subsection{Transmission from vaccinated to naïve, in-contact animals}

The use of emergency vaccination during an outbreak, or epidemic, is primarily to reduce transmission, however, few studies have been designed to specifically investigate transmission of FMDV from vaccinated animals. Donaldson and Kitching [29], using a monovalent $\mathrm{O}_{1}$ BFS 1860 FMD vaccine with an estimated potency of $19 \mathrm{PD}_{50}$ assessed transmission to naïve cattle from cattle vaccinated between four and 21 days prior to challenge (Tab. VII). All 18 cattle, vaccinated 21 days before challenge, remained free from clinical disease and although four were shown to be sub-clinically infected, there was no transmission to in-contact susceptible cattle. One of the two groups of cattle, vaccinated 14 days prior to challenge, transmitted sub-clinical infection, but not disease, to susceptible animals housed with them from the day after challenge. Shorter periods of either 4 or 7 days between vaccination and challenge resulted in transmission of disease from clinically normal vaccinated to incontact animals in 1 of the 2 experiments. The additional challenge presented by these diseased in-contact animals then overwhelmed the immunity of the vaccinated animals. Subsequent disease was, however, less severe in these animals and lesions only occurred in the head region. The authors concluded that during emergency vaccination programs it would be advisable to vaccinate all FMD susceptible animals within the vaccination zone and that at the boundary of the zone the vaccinated animals should be kept separate from unvaccinated animals for at least three weeks. 
Table VII. Summary table to show transmission from vaccinated or unvaccinated animals to naïve, in contact animals.

\begin{tabular}{|c|c|c|c|c|c|c|c|}
\hline \multirow[b]{2}{*}{ Species } & \multirow[b]{2}{*}{ Vaccine } & \multirow[b]{2}{*}{ Challenge } & \multicolumn{2}{|c|}{ Donor } & \multicolumn{2}{|c|}{ Recipient } & \multirow[b]{2}{*}{ Reference } \\
\hline & & & $\begin{array}{c}\text { Days } \\
\text { vaccinated } \\
\text { before } \\
\text { exposure }\end{array}$ & $\begin{array}{l}\text { Clinical disease } \\
\text { and/or virus } \\
\text { recovery after } \\
\text { challenge }\end{array}$ & $\begin{array}{c}\text { Contact } \\
\text { began }\end{array}$ & $\begin{array}{c}\text { Clinical } \\
\text { disease } \\
\text { and/or virus } \\
\text { recovery }\end{array}$ & \\
\hline \multirow{13}{*}{ Cattle } & & & 21 & $0 / 3^{\mathrm{a}}$ & $1^{\mathrm{b}}$ & $0 / 2$ & \multirow{13}{*}{ [29] } \\
\hline & & & 21 & $0 / 3$ & 7 & $0 / 2$ & \\
\hline & & & 21 & $0 / 3$ & 23 & $0 / 2$ & \\
\hline & & & 21 & $0 / 3$ & 1 & $0 / 2$ & \\
\hline & $\mathrm{O}_{1} \mathrm{BFS}$ & Homologous & 21 & $1 / 3$ & 1 & $0 / 2$ & \\
\hline & 1860 & indirect & 21 & $3 / 3$ & 7 & $0 / 2$ & \\
\hline & $10 \mu \mathrm{g} / \mathrm{dose}$ & aerosol from 2 & 14 & $0 / 3$ & 1 & $2 / 2$ & \\
\hline & \multirow[t]{6}{*}{ Aqueous } & donor pigs & 14 & $2 / 3$ & 1 & $0 / 2$ & \\
\hline & & for $1 \mathrm{~h}$ & 7 & $0 / 3$ & 1 & $1 / 2$ & \\
\hline & & & 7 & $3 / 3$ & 1 & $2 / 2$ & \\
\hline & & & 4 & $0 / 3$ & 1 & $2 / 2$ & \\
\hline & & & 4 & $3 / 3$ & 1 & $2 / 2$ & \\
\hline & & & 0 & $12 / 12$ & 1 & $8 / 8$ & \\
\hline \multirow{10}{*}{ Pigs } & $\mathrm{C}_{1}$ & Homologous & 7 & $0 / 3$ & 1 & $0 / 2$ & \multirow{6}{*}[57]{} \\
\hline & Oberbayern & indirect & 5 & $2 / 3$ & 1 & $2 / 2$ & \\
\hline & $2.9 \mu \mathrm{g} / \mathrm{dose}$ & aerosol from 3 & 4 & $2 / 3$ & 1 & $2 / 2$ & \\
\hline & Oil & donor pigs for & 3 & $3 / 3$ & 1 & $2 / 2$ & \\
\hline & & $4 \mathrm{~h}$ & 2 & $3 / 3$ & 1 & $2 / 2$ & \\
\hline & & & 0 & $2 / 2$ & 1 & $2 / 2$ & \\
\hline & $\mathrm{O}_{1}$ & Homologous & 6 & $3 / 3$ & 1 & $2 / 2$ & \multirow{4}{*}{ [7] } \\
\hline & Lausanne & direct contact & 5 & $3 / 3$ & 1 & $2 / 2$ & \\
\hline & $6.1 \mu \mathrm{g} / \mathrm{dose}$ & with 3 pigs for & 4 & $3 / 3$ & 1 & $2 / 2$ & \\
\hline & Oil & $2 \mathrm{~h}$ & 0 & $3 / 3$ & 1 & $2 / 2$ & \\
\hline \multirow{11}{*}{ Sheep } & Asia 1 & & 10 & $2 / 3$ & 1 & $1 / 2$ & \multirow{11}{*}{ [19] } \\
\hline & India & Homologous & 6 & $2 / 3$ & 1 & $1 / 2$ & \\
\hline & 5.25 & indirect & 4 & $0 / 3$ & 1 & $0 / 2$ & \\
\hline & $\mu \mathrm{g} /$ dose & Aerosol from 3 & 3 & $0 / 3$ & 1 & $1 / 2$ & \\
\hline & Oil & pigs for $4 \mathrm{~h}$ & 0 & $3 / 3$ & 1 & $2 / 2$ & \\
\hline & & & & & & & \\
\hline & & & 11 & $0 / 3$ & 1 & $0 / 2$ & \\
\hline & $\mathrm{C}_{1}$ & Homologous & 7 & $0 / 3$ & 1 & $0 / 2$ & \\
\hline & Oberbayern & indirect & 5 & $1 / 3$ & 1 & $0 / 2$ & \\
\hline & $1.4 \mu \mathrm{g} / \mathrm{dose}$ & Aerosol from 3 & 4 & $0 / 3$ & 1 & $0 / 2$ & \\
\hline & Aqueous & pigs for $4 \mathrm{~h}$ & 0 & $2 / 3$ & 1 & $2 / 2$ & \\
\hline
\end{tabular}

${ }^{\mathrm{a}}$ Number of animals clinically diseased or from which virus recovered/total number of animals, ${ }^{\mathrm{b}}$ number of days after vaccinated animals challenged.

A similar study using pigs was performed during the 1990's and showed that immunization at seven days prior to challenge prevented clinical disease, reduced airborne excretion of FMDV and prevented contact transmission to susceptible in-contact pigs (Tab. VII) [57]. As with cattle, pigs vaccinated only four days before challenge, although protected from clinical disease, were shown to be capable of transmitting FMDV to in-contact susceptible

Page 18 of 30 (page number not for citation purpose) 
pigs, which then excreted sufficient FMDV to cause foot lesion development in two of the vaccinated pigs, although these lesions were considered primary in nature. Again, it was concluded that vaccinated animals should not be mixed with susceptible animals for at least seven days after vaccination to prevent transmission of infection. A more recent study using pigs vaccinated 4,5 and 6 days before direct contact challenge showed transmission of FMDV to all susceptible in-contact pigs despite the levels of virus excretion being reduced, as compared with the levels of FMDV excreted from the infected unvaccinated controls (Tab. VII) [7]. This was perhaps to be expected, since most of the vaccinated pigs also exhibited clinical disease. However, since pigs pose the main threat of amplification and rapid dissemination of airborne FMDV, these results provided evidence that vaccination within an infected area (suppressive vaccination), to reduce the amount of virus circulating, might be a useful aid to controlling airborne spread during an outbreak. This dampening down of virus excretion could be particularly useful in areas of high pig density, where the logistics of mass slaughter and disposal of carcasses might prove difficult.

Likewise, some of the previously mentioned vaccine studies on sheep investigated transmission of FMDV to naïve in-contact sheep from animals vaccinated at different times before challenge [19]. Studies using an oil formulated Asia 1 India vaccine demonstrated transmission to in-contact sheep from animals vaccinated at 10, 6 and 3 days before challenge, where as use of both oil and aqueous formulated $\mathrm{C}_{1}$ Oberbayern vaccines prevented transmission to in-contacts, even in the group where one vaccinated animal was consistently shown to be sub-clinically infected (Tab. VII). It was concluded that these higher potency vaccines could reduce, but not totally prevent, contact transmission.

\subsection{Transmission between homogeneously treated groups of animals}

More recent studies carried out in The Netherlands have attempted to quantify the reduction of transmission of FMDV. This has been done by estimating the reproduction ratio $\mathrm{R}$ (i.e., the average number of secondary cases caused by one infectious animal in a susceptible population) and/or alternatively the daily transmission rate, $\beta$ and the infectious period $\mathrm{T}$, for different intervals between vaccination and FMDV challenge. These studies differed from those described earlier in that they considered transmission from vaccinated to vaccinated, or unvaccinated to unvaccinated animals.

In an initial pig study, in which animals were allowed direct contact with each other for 14 days following homologous challenge, no transmission was observed in the group vaccinated 14 days before challenge [30] (Tab. VIII). Virus transmission, however, was shown to occur within the group vaccinated 7 days before challenge. This, and other studies, in which both intra-typic heterologous and homologous vaccination were used 14 days prior to challenge [31] (Tab. VIII) or where a 4-fold vaccine dose was used 7 days prior to challenge [32] (Tab. VIII), have been used in meta-analyses to quantify transmission parameters of FMDV strain $\mathrm{O}$ Taiwan among non-vaccinated and vaccinated pigs [33]. From these studies it was concluded that vaccination of pigs would be an effective tool to reduce the transmission of FMDV as early as one week post vaccination. Table IX provides a summary of the estimated transmission parameters $\beta$ (calculated using generalised linear modeling), $\mathrm{T}$ (by using survival analysis) and the reproduction ratio R. However, these experiments also showed that intradermal injection of pigs with FMDV, 14 days after vaccination, was not suitable to start an infection chain, so several additional experiments were carried out in which vaccinated pigs were exposed to infected seeder pigs to calculate similar transmission parameters (Tabs. VIII and IX) [46]. The revised transmission design and challenge method more readily allowed quantification of transmission of FMDV among vaccinated pigs, but according to this study it was concluded that a single vaccination was not sufficient to stop pig to pig virus transmission 
Table VIII. Summary table to show transmission between homogeneously treated groups of animals.

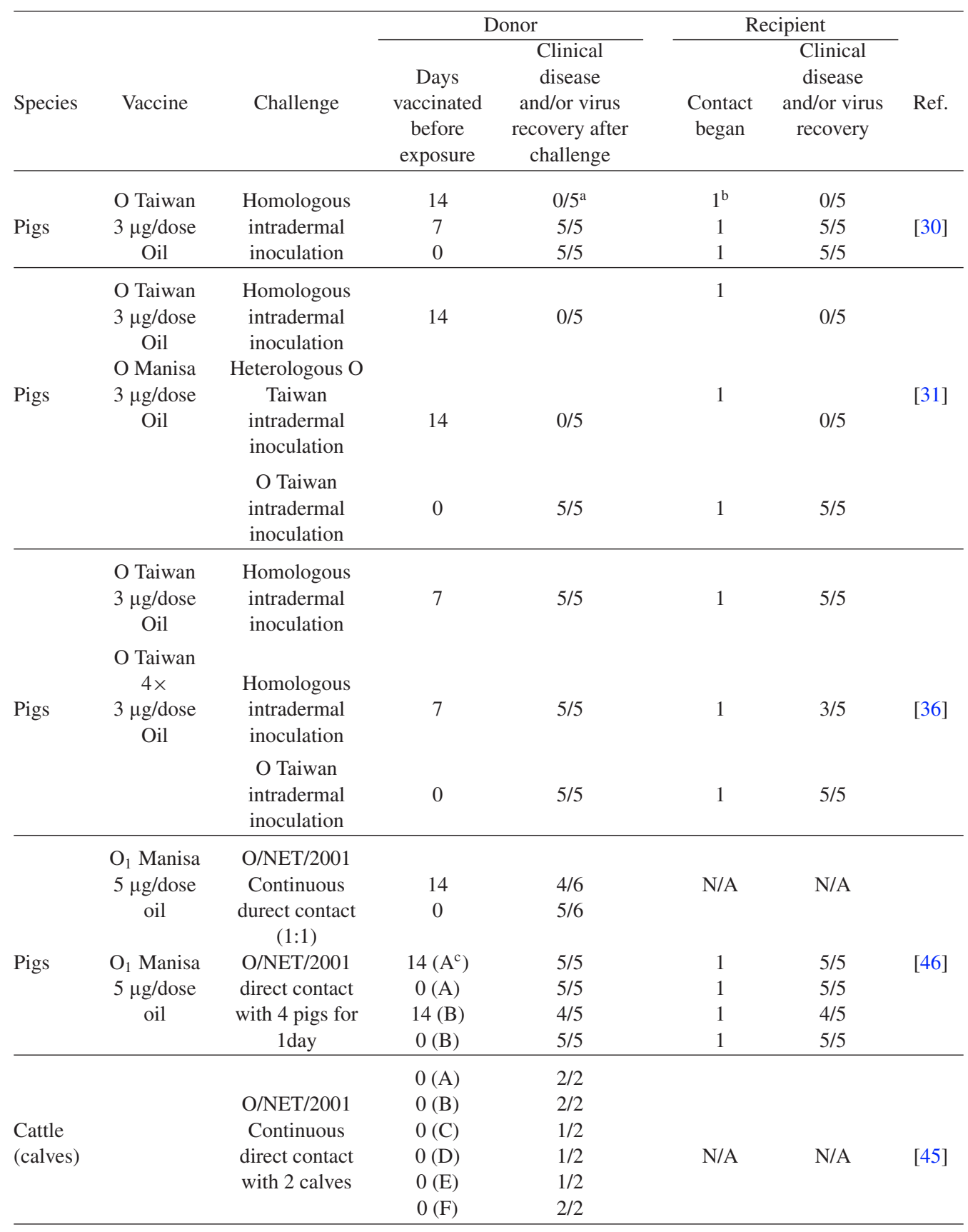

Page 20 of 30 (page number not for citation purpose) 
Table VIII. Continued.

\begin{tabular}{|c|c|c|c|c|c|c|c|}
\hline \multirow{3}{*}{ Species } & \multirow[b]{2}{*}{ Vaccine } & \multirow[b]{2}{*}{ Challenge } & \multicolumn{2}{|c|}{ Donor } & \multicolumn{2}{|c|}{ Recipient } & \multirow[b]{2}{*}{ Ref. } \\
\hline & & & $\begin{array}{c}\text { Days } \\
\text { vaccinated } \\
\text { before } \\
\text { exposure }\end{array}$ & $\begin{array}{c}\text { Clinical } \\
\text { disease } \\
\text { and/or virus } \\
\text { recovery after } \\
\text { challenge }\end{array}$ & $\begin{array}{c}\text { Contact } \\
\text { began }\end{array}$ & $\begin{array}{c}\text { Clinical } \\
\text { disease } \\
\text { and/or virus } \\
\text { recovery }\end{array}$ & \\
\hline & $\begin{array}{c}\mathrm{O}_{1} \text { Manisa } \\
\text { Oil } \\
11 \mathrm{PD}_{50}\end{array}$ & $\begin{array}{l}\mathrm{O} / \mathrm{NET} / 2001 \\
\text { Continuous } \\
\text { direct contact } \\
\text { with } 2 \text { calves }\end{array}$ & $\begin{array}{l}14(\mathrm{~A}) \\
14(\mathrm{~B}) \\
14(\mathrm{C}) \\
14(\mathrm{D}) \\
14(\mathrm{E}) \\
14(\mathrm{~F})\end{array}$ & $\begin{array}{l}1 / 2 \\
0 / 2 \\
0 / 2 \\
0 / 2 \\
0 / 2 \\
0 / 2\end{array}$ & N/A & N/A & \\
\hline $\begin{array}{l}\text { Cattle } \\
\text { (dairy) }\end{array}$ & $\begin{array}{c}\mathrm{O}_{1} \text { Manisa } \\
\text { Oil } \\
9 \mathrm{PD}_{50}\end{array}$ & $\begin{array}{l}\text { O/NET/2001 } \\
\text { Continuous } \\
\text { direct contact } \\
\text { with } 5 \text { cattle } \\
\text { O/NET/2001 } \\
\text { Continuous } \\
\text { direct contact } \\
\text { with } 5 \text { cattle }\end{array}$ & $\begin{array}{l}0(\mathrm{~A}) \\
0(\mathrm{~B}) \\
14(\mathrm{~A}) \\
14(\mathrm{~B})\end{array}$ & $\begin{array}{l}5 / 5 \\
5 / 5\end{array}$ & N/A & N/A & [47] \\
\hline $\begin{array}{l}\text { Sheep } \\
\text { (lambs) }\end{array}$ & $\begin{array}{c}\mathrm{O}_{1} \text { Manisa } \\
\text { Oil } \\
6 \mathrm{PD}_{50}\end{array}$ & $\begin{array}{l}\text { O/NET/2001 } \\
\text { Continuous } \\
\text { direct contact } \\
\text { with } 2 \text { lambs }\end{array}$ & $\begin{array}{c}0(\mathrm{~A}) \\
0(\mathrm{~B}) \\
0(\mathrm{C}) \\
0(\mathrm{D}) \\
0(\mathrm{E}) \\
0(\mathrm{~F}) \\
14(\mathrm{G}) \\
14(\mathrm{H}) \\
14(\mathrm{I}) \\
14(\mathrm{~J}) \\
14(\mathrm{~K}) \\
14(\mathrm{~L})\end{array}$ & $\begin{array}{l}1 / 2 \\
0 / 2 \\
0 / 2 \\
2 / 2 \\
0 / 2 \\
2 / 2 \\
0 / 2 \\
1 / 2 \\
0 / 2 \\
0 / 2 \\
0 / 2 \\
0 / 2\end{array}$ & N/A & N/A & [48] \\
\hline Sheep & $\begin{array}{c}\mathrm{O}_{1} \text { Manisa } \\
?(18 \\
\mathrm{PD}_{50} \text { for } \\
\text { cattle }) \\
\text { Oil }\end{array}$ & $\begin{array}{c}\text { Semi- } \\
\text { heterologous } \\
\text { indirect aerosol } \\
\text { from } 3 \text { infectious } \\
\text { pigs for } 9 \mathrm{~h}\end{array}$ & $\begin{array}{c}10 \\
4 \\
0\end{array}$ & $\begin{array}{c}7 / 10 \\
8 / 10 \\
8 / 8\end{array}$ & $\begin{array}{c}2 \\
2 \\
\text { N/A }\end{array}$ & $\begin{array}{r}1 / 4 \\
1 / 4 \\
\text { N/A }\end{array}$ & [52] \\
\hline
\end{tabular}

a Number of animals clinically diseased or from which virus recovered/total number of animals, ${ }^{\mathrm{b}}$ number of days after vaccinated animals challenged, ${ }^{\mathrm{c}}$ replicate, ${ }^{\mathrm{d}}$ donor animals vaccinated before intranasal inoculation.

within a group of pigs, and that major outbreaks may still be expected even within groups of vaccinated pigs, although $\mathrm{R}$ was largely reduced by vaccination.

An experiment with calves was also performed to determine whether FMDV could be passed between those with limited contact, as during the 2001 outbreak in The Netherlands there appeared to be limited transmission between animals on two infected veal-calf farms [13]. The study confirmed that no transmission of FMDV occurred, despite recovery of virus from those animals initially infected. The authors, however, emphasized, on several occasions, the dangers of extrapolating results from experiments such as these, and since $\mathrm{R}$ was not significantly below 1 (Tab. IX) suggested that major outbreaks could not be ruled out, for the strain O/NET/2001. It was concluded during this study that it might have been more logical to allow free mingling of calves, and hence a follow up study [45] using both unvaccinated and vaccinated calves was 
Table IX. Summary of parameter estimates for transmission rate $\beta$, infectious period $\mathrm{T}$ and reproduction ratio R of FMDV among non-vaccinated and vaccinated animals.

\begin{tabular}{|c|c|c|c|c|c|c|}
\hline Species & No. experiments & Groups & $\beta(\mathrm{CI})$ & $\mathrm{T}(\mathrm{CI})$ & $\mathrm{R}(\mathrm{CI})$ & Ref. \\
\hline \multirow[t]{5}{*}{ Pig } & 4 & Non-vaccinated & $6.1(3.7-10.1)$ & $6.5(5.7-7.3)$ & $40(21-74)$ & \multirow{5}{*}{ [33] } \\
\hline & 2 & Vaccinated -7 dpi & $2.0(1.0-4.0)^{*}$ & $5.3(4.7-6.0)^{*}$ & $11(4.9-24)^{*}$ & \\
\hline & 1 & Vaccinated $-7 \mathrm{dpi}, 4 \mathrm{FD}$ & $0.4(0.1-1.4)^{*}$ & $2.3(0.9-5.7)^{*}$ & $1.0(0.1-7.8)^{*}$ & \\
\hline & 2 & Vaccinated - 14 dpi & n.c. & n.c. & n.c. & \\
\hline & 1 & Vaccinated - $14 \mathrm{dpi}$, het & n.c. & n.c. & n.c. & \\
\hline \multirow[t]{3}{*}{ Pig } & & Non-vaccinated & n.c. & n.c. & $10.00(1.2-\infty)$ & \multirow{3}{*}{ [46] } \\
\hline & Exp. 1 & $\begin{array}{l}\text { Vaccinated - } 14 \mathrm{dpi} \\
\text { Non-vaccinated }\end{array}$ & $\begin{array}{c}\text { n.c. } \\
6.84(3.17-14.75)\end{array}$ & $\begin{array}{l}\text { n.c. } \\
\text { n.c. }\end{array}$ & $\begin{array}{c}\text { n.c. } \\
\infty(1.3-\infty)\end{array}$ & \\
\hline & Exp. 2 & Vaccinated - 14 dpi & $0.66(0.24-1.82)^{*}$ & n.c. & $2.42(0.9-6.9)$ & \\
\hline Cattle (calves) & 2 & Non-vaccinated & n.c. & n.c. & $0(0-3.03)$ & [13] \\
\hline \multirow[t]{2}{*}{ Cattle (calves) } & 2 & Non-vaccinated & n.c. & n.c. & $2.52(1.13-52.1)$ & \multirow[t]{2}{*}{ [45] } \\
\hline & 1 & Vaccinated - 14 dpi & n.c. & n.c. & $0.18(0.01-1.2)^{*}$ & \\
\hline \multirow[t]{2}{*}{ Cattle (dairy) } & 2 & Non-vaccinated & n.c. & n.c. & $\infty(1.3-\infty)$ & \multirow[t]{2}{*}{ [47] } \\
\hline & 1 & Vaccinated-14dpi & n.c. & n.c. & $0(0.0-3.4)^{*}$ & \\
\hline \multirow[t]{2}{*}{ Sheep } & 1 & Non-vaccinated & $0.105(0.044-0.253)$ & $21.1(10.6-42.1)$ & $1.14(0.3-3.3)$ & \multirow[t]{2}{*}{ [48] } \\
\hline & 1 & Vaccinated -14 dpi & n.c. & n.c. & $0.22(0.01-1.78)$ & \\
\hline
\end{tabular}

CI: $95 \%$ confidence interval, n.c.: not calculated, $*$ significantly different $(p<0.01)$ as compared to the non-vaccinated group. 
undertaken (Tab. VIII). In these experiments groups of four calves, either vaccinated two weeks before challenge, or unvaccinated, were allowed to mingle freely. At the time of challenge two animals from each group were inoculated intra-nasally with FMDV O/NET/2001 and then $20 \mathrm{~h}$ later reunited with the other two calves in their group, thereby subjecting these animals to contact exposure. FMDV transmission from inoculated animals to un-inoculated calves occurred in all the nonvaccinated groups but not to all contact calves. In the vaccinated groups, virus transmission was limited to one in-contact calf. The estimated $\mathrm{R}$ values for each group are given in Table IX, and indicate that vaccination would be successful as an additional tool to control transmission of FMDV in an outbreak. A more recent follow on study, designed to investigate whether virus transmission is also significantly reduced among adult dairy cattle following a single application of emergency vaccine (Tab. VIII) [47], has also concluded that vaccination is effective in reducing virus transmission (Tab. IX). A significant difference was shown in virus transmission in vaccinated and non-vaccinated groups of lactating cows.

A similar study has also been carried out in sheep [48] (Tab. VIII). In these experiments groups of four lambs, either vaccinated two weeks before challenge or unvaccinated were allowed to mingle freely. At the time of challenge, two lambs from each group were inoculated and the other half contact exposed to the inoculated animals for 30 days. The estimated $\mathrm{R}$ values are given in Table IX. Virus transmission, as quantified by the reproduction ratio $\mathrm{R}$ using the final size method, did not differ statistically between the vaccinated and non-vaccinated groups of lambs. The data suggested that FMDV can persist in a sheep population. However, as the reproduction ratio was only slightly above 1 for unvaccinated animals, it was concluded that vaccination might only have a small effect on transmission, in spite of the fact that virus excretion and duration of virus excretion was significantly reduced after vaccination. In another study [52], virus transmission from vaccinated sub-clinically infected sheep to introduced vaccinated sentinels was shown not to be sufficient to cause non-structural protein seroconversion or significant virus shedding (Tab. VIII), and it was concluded that the spread of infection would be controlled, even under intensive management conditions, in flocks which had only recently been vaccinated 4 days prior to challenge.

\section{DURATION OF IMMUNITY FOLLOWING A SINGLE APPLICATION OF VACCINE}

Ideally vaccines should be capable of stimulating a potent long lasting immunity after a single vaccination and much research effort has been directed towards improving FMD vaccines and understanding the host's immune responses to natural infection in order to achieve this (as reviewed by [11,26,27]). However, depending upon the type and quality, the often lower potency vaccines applied conventionally for prophylactic use in endemic areas provide immunity that often lasts no longer than 4-6 months in the absence of booster doses. The main requirement of vaccines for emergency use has been to rapidly induce protective immunity in animals following a single shot, as a means of controlling viral spread. Thus, the main thrust of early research was directed at assessing how early protection could be achieved in animals which eventually would be culled. However, recently there has been a shift away from control policies that encompass a vaccinate-to-cull with preference toward vaccinate-to-live strategies. Consequently, studies to investigate duration of protective immunity against FMD following a single application of vaccine in an emergency will be important in order to provide information for dealing with prolonged outbreaks affecting emergency vaccinated livestock.

Using South African Territories serotype vaccines, studies in cattle have shown that vaccines formulated with either Montanide ISA 25 or ISA 206 oil adjuvants elicited a high level of antibodies which were maintained for at least six months [39] whereas another study in cattle using similar adjuvanted serotype A24 Cruzeiro vaccines, failed to demonstrate 
a long duration of immunity, as antibody titres were waning by 43 days post vaccination [4]. Subsequently, a study in sheep (Trial 1), in which groups of three animals received either oil or aqueous $\mathrm{O}_{1}$ Manisa or $\mathrm{A}_{22}$ Iraq vaccine formulations, showed that following a single application, the specific antibody levels against both vaccine strains could remain high for up to 168 days post vaccination, particularly where an oil based formulation was used [20]. Additionally, a recent study using several oil adjuvanted vaccines containing either $\mathrm{O}_{1}$ Manisa, A Turkey 14/98 or Asia 1 Shamir has also confirmed durability of the antibody response for at least 6 months ${ }^{5}$. To date there have been no published experiments in either cattle or sheep immunized with a single dose of higher potency vaccine and then challenged at a time point beyond 28 days post vaccination to assess long-term protection. However, recent work by the authors using a high potency, oil adjuvanted A22 vaccine, in which 20 cattle received a homologous intradermolingual challenge 6 months post vaccination, showed that animals were protected from clinical disease (unpublished observation). Further experiments are planned using different FMDV serotypes.

In contrast to the ruminant studies, pigs have been examined in slightly greater detail for long-term immunity following a single immunization with higher potency vaccine [20]. In groups of three pigs it was demonstrated that antibody levels were maintained for up to 218 days. A second trial, which used groups of four pigs, included an indirect contact challenge from pigs infected with $\mathrm{C}_{1}$ Oberbayern. Pigs that received a homologous challenge at 215 days post vaccination showed no signs of clinical disease whereas those animals vaccinated with the heterologous strain, $\mathrm{O}_{1}$ Lausanne, showed typical signs of FMD. This indicated that the required protective immunity against

\footnotetext{
${ }^{5}$ Selman P., Chenard G., Dekker A., Cedivac-FMD: Duration of immunity in cattle, sheep and pigs, Rep. Session Res. Group Standing Techn. Comm. Eur. Comm. Contr. FMD, Paphos, Cyprus, FAO, Rome, 2006, Appendix 31, pp. 215-219.
}

FMD could be maintained for at least 7 months in this species. The recent study ${ }^{5}$ also demonstrated that high levels of antibody were maintained in pigs for at least 6 months following a single dose of vaccine.

\section{GENERAL DISCUSSION}

The work reviewed has provided valuable insight on how efficacious vaccines might be for emergency use in cattle, sheep and pigs. There are many variables implicit in vaccine/challenge studies including relative strength of vaccine dose, vaccine/challenge interval and challenge severity, itself dependent on weight, route and match of challenge. Likewise, measures of outcome/success are several, including options to measure clinical protection, virus replication/excretion and virus transmission. The very nature of FMD, its host range and differences in serotype, pathogenesis, and modes of transmission complicate study design and make experiments supposedly simulating field scenarios difficult. The summary tables included in this review show the variation in experimental design and exemplify how difficult it is to draw definitive conclusions on FMD vaccine efficacy, and in reality, only broad conclusions can be drawn. In more recent studies [21-23, 51, 52], there has been a shift towards using 'worst case scenario' involving longer, direct contact challenges with viruses that are semi-heterologous to the vaccine strains, with the hope that if a good result can be obtained then the outcome of less severe challenge scenarios should at least be equal if not better.

It is thus difficult to compare experiments directly, though the data shows that a single shot of vaccine with relatively high antigen payload, is capable of protecting all three species from clinical disease, and that ruminants will most likely be protected sooner than pigs. Funding limitations and the expense of performing large animal experiments in disease secure isolation facilities have limited the numbers of animals used in many of the studies, which makes statistical interpretation of data difficult. However, it has been possible to show that challenge dose/duration of 
exposure and the length of time between vaccination and challenge with FMDV are all important in determining whether protection is achieved. For all species, the lighter the challenge and the longer the period between vaccination and challenge, the more likely animals are to be protected, although the data does suggest that pigs are more difficult to protect from clinical disease early after vaccination, once they become infected.

Also important is the prevention of subclinical infection and/or reduction in virus excretion, which in the absence of clinical disease could go unnoticed. The experimental evidence suggests that FMD vaccines, following a single administration, can sometimes prevent sub-clinical infection in cattle, sheep and pigs, but usually reduce virus replication and shedding compared to unvaccinated and vaccinated but clinically affected animals. As for clinical protection, the greater the period between vaccination and challenge and the less severe the challenge, then the less likely virus will be recovered. Non structural protein serology appears to be a useful indicator of the extent of virus replication in subclinically infected animals. Lacking at present is quantitative data with regard to the effect of vaccination on reduction of FMDV excretion in breath. Such information would be particularly useful for pigs, since they are considered the main amplifiers of FMDV and therefore potentially an important source of airborne spread.

There has quite rightly also been a shift away from investigating clinical protection towards investigation of the ability of FMD vaccines to reduce transmission, which after all, is the principle aim of vaccine application in an emergency situation. The studies reviewed suggest that good quality FMD vaccines are able to reduce transmission from vaccinated animals to both naïve and vaccinated animals when held in direct contact with each other, although on occasion a single vaccination was not sufficient to stop virus transmission completely, suggesting that some transmission may still be expected, even in groups of vaccinated animals. However, because most results are from within pen transmission experiments it may be hypothesized that transmission of FMDV between herds during an outbreak when movement restrictions are in place, would be less likely than shown experimentally, since the exposure dose and contact rate between herds will be reduced. Hence the data strongly suggests that transmission from vaccinated animals between premises would be extremely limited. As would be expected, the transmission data complements the sub-clinical data in that the greater the period between vaccination and challenge the less likely transmission was observed.

More carefully designed transmission experiments to investigate indirect transmission are required, along the lines of those carried out in The Netherlands [30-32,45-48] particularly with regard to using shorter intervals between vaccination and challenge and between species Additionally, retrospective meta-analyses of the aforementioned studies not specifically designed to investigate transmission within projects, should also be encouraged. This will provide amongst others, transmission parameter estimates for use in FMD modeling exercises, and further assist policy makers in national governments, the EU and worldwide on appropriate control strategies. Particularly useful will be quantifying the reduction in transmission of FMDV by estimating the reproduction ratio for different intervals between vaccination and FMDV infection. The move towards using larger group sizes in more recent studies has also enabled not only more statistical analysis but also provided data more suitable for use by modelers, for example, a recent paper to estimate the prevalence of FMD carriers after reactive vaccination [3]. However, more consistency in future experimental designs would further aid subsequent interpretation of data generated from different experiments.

The closeness of match between the outbreak strain and the vaccine applied will affect vaccine performance in an emergency situation, and more recent experimental work has attempted to also address the issue that outbreaks will involve isolates not homologous to the vaccine strain by using heterologous 
challenges $[1,14,21-23,31,45-48]^{6}$. It is vitally important to match outbreak strains to the most appropriate vaccine held in an emergency vaccine bank, and world wide monitoring of field isolates, and in vitro antigenic matching studies continue, to ensure the most appropriate antigen stocks are held [53]. The potency testing of such stocks, however, generally involves homologous challenge, so these experimental studies with heterologous challenges have provided useful information on cross-protection following a single immunization with vaccine. Arguably in the future, studies should continue to use heterologous challenges in order to better represent the field situation.

More studies are required to substantiate the importance of antigen payload, both in terms of providing improved protection from subclinical infection and perhaps broader cross reactivity within serotype, and to further elucidate the immune mechanisms involved in early protection from both disease and subclinical infection. Nevertheless, it is clear from completed studies that the presently available emergency vaccines should be used more readily as an additional tool for control of FMD in cattle, sheep and pigs than they are at present. Since the 2001 FMD outbreaks in the EU, in which millions of animals were culled and destroyed, provoking discussion on the ethics of a non-vaccination policy, there has been a subsequent shift in EU policy toward recognizing that emergency vaccination offers an additional and publicly more acceptable alternative. The findings of many of the studies reviewed suggest however, that effectiveness at providing protection from disease and preventing transmission (by reducing or preventing FMDV excretion), is very much related to the duration between vaccination and subsequent encounter with FMDV. Therefore, if

${ }^{6}$ Srinivasan V.A., Nagendra Kumar S.B., Madhan M., Mohan V., Maroudam V., Santha Kumar P., et al., Preliminary results to evaluate crossprotection between O1 Manisa and O1 Campos in cattle, Rep. Session Res. Group Standing Techn. Comm. Eur. Comm. Contr. FMD, Paphos, Cyprus, FAO, Rome, 2006, Appendix 30, pp. 207-214. vaccination is to be employed in an outbreak, the decision to do so must avoid delay, and thus provide maximum opportunity for immunity to develop. Challenge dose will of course also be important in determining whether animals become infected, but continued imposition of movement restrictions should ensure most transmission would be limited to indirect methods (low dose) rather than by additional direct contact. The directive 2003/85/EC thus states that all member countries should have arrangements in place for possible use of emergency vaccination as soon as FMD is confirmed. Additionally, in order to support a 'vaccination to live' strategy, the infected countries disease free status may now be regained earlier, at six months after the last vaccination, providing absence of infection can be demonstrated [44]. Consequently, and as a priority, work continues to be directed at developing and evaluating improved assays for the differentiation of vaccinated-only from infected animals $[15,49,50,54]$.

Nowadays, not only is information required on early responses but, owing to the change in EU policy toward 'vaccinate-to-live,' there is also a need for information on the duration of the response following a single immunization. Durability of response has been a rather neglected area of research, but the limited studies carried out in sheep and pigs [20], and the more recent unpublished work in cattle, suggest that higher potency oil adjuvanted vaccines promote a longer lasting response than seen for lower potency vaccines. Further work is necessary in both pigs and ruminants to substantiate these results and confirm that a single application of vaccine could confer protection for the average length of an outbreak, avoiding the need to revaccinate. If longer durability can be proved, the possibility of using higher potency vaccines in FMD endemic areas of the world could be considered in order to reduce the frequency of vaccine application, perhaps making eradication by vaccination campaigns more viable. However, the feasibility of such a scheme may also be dependent on the development of more cost effective vaccine production methods.

Page 26 of 30 (page number not for citation purpose) 
Although the development of novel FMD vaccines remains high on the agenda for many FMD laboratories worldwide, as exemplified by developments in adenovirus vectored vaccines, we are still likely to be dependent on the current inactivated whole viral antigen vaccines for several years. Detailed studies of the efficacy and optimal dosage for presently available vaccines, as well as studies investigating new adjuvants and/or delivery routes, are essential in support of contingency planning and emergency use. Studies previously referred to, comparing aqueous and oil adjuvanted formulations for emergency use in cattle and sheep, support this notion. It is clear from these studies that vaccines formulated with new generation mineral oils perform equally as well as traditionally used aluminium hydroxide/saponin formulations in ruminants, following a single administration. Hence, this work has demonstrated that in an outbreak situation a single, oil formulation of vaccine need only be manufactured and utilized for all three main target species. The other advantages of using oil adjuvanted vaccines are versatility, simplicity of the manufacturing process, and improved shelf-life compared to aqueous formulated vaccines [4], with the potential to store for many years in vaccine banks [8]. Additionally, studies carried out with these vaccines allow further investigation of the various immune parameters important for protection from disease and prevention of sub-clinical infection. Immune defence against virus infection involves both innate and specific (adaptive) phases. Historically, the specific humoral antibody responses have been considered the most important factor conferring protection against FMD, but a clearer understanding of early cell mediated responses following vaccination in vivo and how these correlate with protection is still required. Such knowledge is an essential prerequisite for the optimization of novel vaccine approaches.

It is hoped that future studies may be designed to incorporate the aforementioned areas of interest in order to continue broadening our understanding of how such vaccines work, and how they can be improved and be better applied, particularly in an emergency situation.

Acknowledgements. The authors are grateful to David Paton for reviewing this manuscript. This work was supported by Defra (SE2812). Paul Barnett is a Jenner Institute investigator.

\section{REFERENCES}

[1] Aggarwal N., Zhang Z., Cox S., Statham R., Alexandersen S., Kitching R.P., Barnett P.V., Experimental studies with foot-and-mouth disease virus, strain $\mathrm{O}$, responsible for the 2001 epidemic in the United Kingdom, Vaccine (2002) 20:2508-2515.

[2] Alexandersen S., Zhang Z., Donaldson A.I., Garland A.J.M., The pathogenesis and diagnosis of foot-and-mouth disease, J. Comp. Pathol. (2003) 129:1-36.

[3] Arnold M.E., Paton D.J., Ryan E., Cox S.J., Wilesmith J.W., Modeling studies to estimate the prevalence of foot-and-mouth disease carriers after reactive vaccination, Proc. R. Soc. B (2008) 275:107115 .

[4] Barnett P.V., Pullen L., Williams L., Doel T.R., International bank for foot-and-mouth disease vaccine: assessment of Montanide ISA 25 and ISA 206, two commercially available oil adjuvants, Vaccine (1996) 14:1187-1198.

[5] Barnett P.V., Cox S.J., The role of small ruminants in the epidemiology and transmission of foot-andmouth disease, Vet. J. (1999) 158:6-13.

[6] Barnett P., Garland A.J.M., Kitching R.P., Schermbrucker C.G., Aspects of emergency vaccination against foot-and-mouth disease, Comp. Immunol. Microbiol. Infect. Dis. (2002) 25:345-364.

[7] Barnett P.V., Cox S.J., Aggarwal N., Gerber H., McCullough K.C., Further studies on the early protective responses of pigs following immunization with high potency foot-and-mouth disease vaccine, Vaccine (2002) 20:3197-3208.

[8] Barnett P.V., Statham R.J., Stratified and cryogenically stored (SACS) vaccines, a new concept in emergency foot-and-mouth disease vaccine formulation and storage, Vaccine (2002) 20:2060-2064.

[9] Barnett P.V., Carabin H., A review of emergency foot-and-mouth disease (FMD) vaccines, Vaccine (2002) 20:1505-1514.

[10] Barnett P.V., Keel P., Reid S., Armstrong R.M., Statham R.J., Voyce C., et al., Evidence that high potency foot-and-mouth disease vaccine inhibits local virus replication and prevents the 'carrier' state in sheep, Vaccine (2004) 22:1221-1232. 
[11] Barteling S.J., Vreeswijk J., Developments in foot-and-mouth vaccines. Review, Vaccine (1991) 9:75-88.

[12] Belsham G.J., Distinctive features of foot-andmouth disease virus, a member of the picornavirus family; aspects of virus protein synthesis, protein processing and structure, Prog. Biophys. Mol. Biol. (1993) 60:241-260.

[13] Bouma A., Dekker A., de Jong M.C.M., No foot-and-mouth disease virus transmission between individually housed calves, Vet. Microbiol. (2004) 98:29-36.

[14] Brehm K.E., Kumar N., Thulke H.-H., Haas B., High potency vaccines induce protection against heterologous challenge with foot-and-mouth disease virus, Vaccine (2008) 26:1681-1687.

[15] Brocchi E., Bergmann I.E., Dekker A., Paton D.J., Sammin D.J., Greiner M., et al., Comparative evaluation of six ELISAs for the detection of antibodies to the non-structural proteins of foot-andmouth disease virus, Vaccine (2006) 24:6966-6979.

[16] Callis J.J., McKercher P.D., Graves J.H., Footand-mouth disease - a review, J. Am. Vet. Med. Assoc. (1968) 153:1798-1802.

[17] Casas-Olascoaga R., The history of foot-andmouth disease control in South America, in: Dodet B., Vicari M. (Eds.), Foot-and- mouth disease: control strategies, Elsevier, Paris, 2003, pp. 55-72.

[18] Coetzer J.A.W., Thomsen G.R., Tustin R.C., Kriek N.P.J., Foot-and-mouth disease, in: Coetzer J.A.W., Thomsen G.R, Tustin R.C., Kriek N.P.J. (Eds.), Infectious diseases of livestock with special reference to Southern Africa, Oxford University Press, Cape Town, 1994, pp. 825-852.

[19] Cox S.J., Barnett P.V., Dani P., Salt J.S., Emergency vaccination of sheep against foot-and-mouth disease: protection against disease and reduction in contact transmission, Vaccine (1999) 17:1858-1868.

[20] Cox S.J., Aggarwal N., Statham R.J., Barnett P.V., Longevity of antibody and cytokine responses following vaccination with high potency emergency FMD vaccines, Vaccine (2003) 21:1336-1347.

[21] Cox S.J., Voyce C., Parida S., Reid S.M., Hamblin P.A., Paton D.J., Barnett P.V., Protection against direct contact challenge following emergency FMD vaccination of cattle and the effect on virus excretion from the oropharynx, Vaccine (2005) 23: 1106-1113.

[22] Cox S.J., Voyce C., Parida S., Reid S.M., Hamblin P.A., Hutchings G., et al., Effect of emergency FMD vaccine antigen payload on protection, sub-clinical infection and persistence following direct contact challenge of cattle, Vaccine (2006) 24:3184-3190.
[23] Cox S.J., Parida S., Voyce C., Reid S.M., Hamblin P.A., Hutchings G., et al., Further evaluation of higher potency vaccines for early protection of cattle against FMDV direct contact challenge, Vaccine (2007) 25:40-50.

[24] De Clercq K., Goris N., Barnett P.V., Mackay D.K., FMD Vaccines: Reflections of quality aspects for applicability in European disease control policy, Transbound. Emerg. Dis. (2008) 55:35-45.

[25] Doel T.R., Williams L., Barnett P.V., Emergency vaccination against foot-and-mouth disease: rate of development of immunity and its implication for the carrier state, Vaccine (1994) 12:592-600.

[26] Doel T.R., Natural and vaccine-induced immunity to foot-and-mouth disease: the prospects for improved vaccines, Rev. Sci. Tech. Off. Int. Epizoot. (1996) 15:883-911.

[27] Doel T.R., Optimisation of the immune response to foot-and-mouth disease vaccines, Vaccine (1999) 17:1767-1771.

[28] Doel T.R., FMD vaccines, Virus Res. (2003) 91:81-99.

[29] Donaldson A.I., Kitching R.P., Transmission of foot-and-mouth disease by vaccinated cattle following natural challenge, Res. Vet. Sci. (1989) 46:9-14.

[30] Eblé P.L., Bouma A., de Bruin M.G.M., van Hemert-Kluitenberg F., Van Oirschot J.T., Dekker A., Vaccination of pigs two weeks before infection significantly reduces transmission of foot-and-mouth disease virus, Vaccine (2004) 22:1372-1374.

[31] Eblé P.L., de Bruin M.G.M., Bouma A., van Hemert-Kluitenberg F., Van Oirschot J.T., Dekker A., Comparison of immune responses after intra-typic heterologous and homologous vaccination against foot-and-mouth disease virus in pigs, Vaccine (2006) 24:1274-1281.

[32] Eblé P.L., Bouma A., Weerdmeester J.A., Stegeman J.A., Dekker A., Serological and mucosal immune responses after vaccination and infection with FMDV in pigs, Vaccine (2007) 25:1043-1054.

[33] Eblé P.L., de Koeijer A.A., de Jong M.C.M., Engel B., Dekker A., A meta-analysis quantifying transmission parameters of FMDV strain $\mathrm{O}$ Taiwan among non-vaccinated and vaccinated pigs, Prev. Vet. Med. (2008) 83:98-106.

[34] European Directorate for the Quality of Medicines, European Pharmacopoeia, 6th ed., Vol. 6.0-6.2, Strasbourg, 2008.

[35] Fracastorius H., De contagione et contagiosis morbis et curatione, Book 1, Chap. 12, Venecia, 1546.

[36] Gibson C.F., Donaldson A.I., Ferris N.P., Responses of sheep vaccinated with large doses of 
vaccine to challenge by airborne foot-and-mouth disease virus, Vaccine (1984) 2:157-161.

[37] Gleeson G.L., Samuel A.R., Knowles N.J., Epidemiology of foot-and-mouth disease in Southeast Asia, in: Dodet B., Vicari M. (Eds.), Foot-andmouth disease: control strategies, Elsevier, Paris, 2003, pp. 85-96.

[38] Graves J.H., McKercher P.D., Farris H.E. Jr., Cowan K.M., Early responses of cattle and swine to inactivated foot-and-mouth disease vaccine, Res. Vet. Sci. (1968) 9:35-40.

[39] Hunter P., The performance of Southern African Territories serotypes of foot-and-mouth disease antigen in oil-adjuvanted vaccines, Rev. Sci. Tech. Off. Int Epizoot. (1996) 13:913-922.

[40] Leforban Y., Gerbier G., Recent history and epidemiology of foot-and-mouth disease in Europe, in: Dodet B., Vicari M. (Eds.), Foot-and-mouth disease: control strategies, Elsevier, Paris, 2003, pp. $153-171$.

[41] Loeffler F., Frosch P., Summarischer Bericht über die Ergebnisse der Untersuchungen der Kommoission zur Erforchung der Maul-und-Klamenseuche, Zentralbl. Bakteriol. Parasitenkd. Infektionskr. Hyg. (1897) 22:257-259.

[42] McVicar J.W., Sutmoller P., Growth of foot-andmouth disease virus in the upper respiratory tract of non-immunized, vaccinated and recovered cattle after intranasal inoculation, J. Hyg. (Lond.) (1976) 76:467-481.

[43] Murray J.G., Butler R., Svarcas P.L., Foot-andmouth disease emergency preparedness strategy and evaluation: the Australian perspective, in: Dodet B. Vicari M. (Eds.), Foot-and-mouth disease: control strategies, Elsevier, Paris, 2003, pp. 105-113.

[44] Office International des Epizooties (World Organisation for Animal Health), Foot-and-mouth disease, in: Terrestrial Animal Health Code, 15th ed., OIE, Paris, France, 2006, Chap. 2.2.10.

[45] Orsel K., Dekker A., Bouma A., Stegeman J.A., de Jong M.C.M., Vaccination against foot-and-mouth disease reduces virus transmission in groups of calves, Vaccine (2005) 23:4887-4894

[46] Orsel K., de Jong M.C.M., Bouma A., Stegeman J.A., Dekker A., Foot-and-mouth disease virus transmission among vaccinated pigs after exposure to virus shedding pigs, Vaccine (2007) 25:6381-6391.

[47] Orsel K., de Jong M.C.M., Bouma A., Stegeman J.A., Dekker A., The effect of vaccination on foot-andmouth disease virus transmission among dairy cows, Vaccine (2007) 25:327-335.

[48] Orsel K., Dekker A., Bouma A., Stegeman J.A., de Jong M.C.M., Quantification of foot-and-mouth disease virus excretion and transmission within groups of lambs with and without vaccination, Vaccine (2007) 25:2673-2679

[49] Parida S., Cox S.J., Reid S.M., Hamblin P., Barnett P.V., Inoue T., et al., The application of new techniques to the improved detection of persistently infected cattle after vaccination and contact exposure to foot-and-mouth disease, Vaccine (2005) 23:51865195.

[50] Parida S., Anderson J., Cox S.J., Barnett P.V., Paton D.J., Secretory IgA as an indicator of oropharyngeal foot-and-mouth disease virus replication and as a tool for post vaccination surveillance, Vaccine (2006) 24:1107-1116

[51] Parida S., Fleming L., Oh Y., Mahapatra M., Hamblin P., Gloster J., et al., Reduction of foot-andmouth disease (FMD) virus load in nasal excretions, saliva and exhaled air of vaccinated pigs following direct contact challenge, Vaccine (2007) 25:7806-7817.

[52] Parida S., Fleming L., Oh Y., Mahapatra M., Hamblin P., Gloster J., Paton D.J., Emergency vaccination of sheep against foot-and-mouth disease: significance and detection of subsequent sub-clinical infection, Vaccine (2008) 26:3469-3479.

[53] Paton D.J., Valarcher J.-F., Bergmann I., Matlho O.G., Zakharov V.M., Palma E.L., Thomson G.R., Selection of foot-and-mouth disease vaccine strains - a review, Rev. Sci. Tech. Off. Int. Epizoot. (2005) 24:981-993.

[54] Paton D.J., de Clercq K., Greiner M., Dekker A., Brocchi E., Bergmann I., et al., Application of non-structural protein antibody tests in substantiating freedom from foot-and-mouth disease virus infection after emergency vaccination of cattle, Vaccine (2006) 24:6503-6512.

[55] Pay T.W.F., Hingley P.J., The use of serum neutralizing antibody assay for the determination of the potency of foot-and-mouth disease vaccines in cattle, Dev. Biol. Stand. (1986) 64:153-161.

[56] Rweyemamu M., Roeder P., Mackay D., Sumption K., Brownlie J., Leforban Y., Planning for the progressive control of foot-and-mouth disease worldwide, Transbound. Emerg. Dis. (2008) 55:73-87.

[57] Salt J.S., Barnett P.V., Dani P., Williams L., Emergency vaccination of pigs against foot-and-mouth disease: protection against disease and reduction in contact transmission, Vaccine (1998) 16:746-754.

[58] Sellers R.F., Parker J., Air-borne excretion of foot-and-mouth disease virus, J. Hyg. (Lond.) (1969) 67:671-677.

[59] Sellers R.F., Herniman K.A.J., Early protection of pigs against foot-and-mouth disease, Br. Vet. J. (1974) 130:440-445.

[60] Sellers R.F., Herniman K.A.J., Gumm I.D., The airborne dispersal of foot-and-mouth disease virus

(page number not for citation purpose) Page 29 of 30 
from vaccinated and recovered pigs, cattle and sheep after exposure to infection, Res. Vet. Sci. (1977) 23:70-75.

[61] Sobrino F., Saiz M., Jimenez-Clavero M.A., Nunez J.J., Rosas M.F., Baranowski E., Ley V., Footand-mouth disease: a long known virus, but a current threat, Vet. Res. (2001) 32:1-30.

[62] Sutmoller P., McVicar J.W., Cottral G.E., The epizootiological importance of foot-and-mouth disease carriers. 1. Experimentally produced foot-and-mouth disease carriers in susceptible and immune cattle, Arch. Gesamte Virusforsch. (1968) 23:227-235.
[63] Sutmoller P., Cottral G.E., McVicar J.W., A review of the carrier state in foot-and-mouth disease, Proc. Annu. Meet. US Anim. Health Assoc. (1967) 71:386-395.

[64] Sutmoller P., Barteling S.S., Casas Olascoaga R., Sumption K.J., Control and eradication of foot-and mouth disease, Virus Res. (2003) 91:101-144.

[65] Thomson G.R., Vosloo W., Bastos A.D.S., The epidemiology and control of foot-and-mouth disease in sub-Saharan Africa, in: Dodet B., Vicari M. (Eds.), Foot-and- mouth disease: control strategies, Elsevier, Paris, 2003, pp. 125-134. 